\title{
Seasonal changes of ice surface characteristics and productivity in the ablation zone of the Greenland Ice Sheet
}

\author{
D. M. Chandler ${ }^{1}$, J. D. Alcock ${ }^{1}$, J. L. Wadham ${ }^{1}$, S. L. Mackie ${ }^{2}$, and J. Telling ${ }^{1}$ \\ ${ }^{1}$ Bristol Glaciology Centre, School of Geographical Sciences, Bristol University, Bristol, UK \\ ${ }^{2}$ School of Earth Sciences, Bristol University, Bristol, UK \\ Correspondence to: D. M. Chandler (davemchandler@gmail.com)
}

Received: 3 February 2014 - Published in The Cryosphere Discuss.: 25 February 2014

Revised: 28 January 2015 - Accepted: 31 January 2015 - Published: 6 March 2015

\begin{abstract}
Field and remote sensing observations in the ablation zone of the Greenland Ice Sheet have revealed a diverse range of ice surface characteristics, primarily reflecting the variable distribution of fine debris (cryoconite). This debris reduces the surface albedo and is therefore an important control on melt rates and ice sheet mass balance. Meanwhile, studies of ice sheet surface biological processes have found active microbial communities associated with the cryoconite debris, which may themselves modify the cryoconite distribution. Due to the considerable difficulties involved with collecting ground-based observations of the ice surface, our knowledge of the physical and biological surface processes, and their links, remains very limited. Here we present data collected at a field camp established in the ice sheet ablation zone at $67^{\circ} \mathrm{N}$, occupied for almost the entire melt season (26 May-10 August 2012), with the aim of gaining a much more detailed understanding of the physical and biological processes occurring on the ice surface. These data sets include quadrat surveys of surface type, measurements of ice surface ablation, and in situ biological oxygen demand incubations to quantify microbial activity. In addition, albedo at the site was retrieved from AVHRR (Advanced Very High Resolution Radiometer) remote sensing data. Observations of the areal coverage of different surface types revealed a rapid change from complete snow cover to the "summer" (summer study period) ice surface of patchy debris ("dirty ice") and cryoconite holes. There was significant correlation between surface albedo, cryoconite hole coverage and surface productivity during the melt season, but microbial activity in "dirty ice" was not correlated with albedo and varied widely throughout the season. While this link suggests the potential for a remote-sensing approach to monitoring cry-
\end{abstract}

oconite hole biological processes, very wide seasonal and spatial variability in net surface productivity demonstrates the need for caution when extrapolating point measurements of biological processes to larger temporal or spatial scales.

\section{Introduction}

The ablation zone of the Greenland Ice Sheet displays a remarkable variety of surface characteristics that vary widely in time and space. The varying distribution of ice, snow, melt water and sediment across the surface strongly influences the surface energy balance, and therefore the melt rate and mass balance (e.g. Konzelmann and Braithwaite, 1995; Knap and Oerlemanns, 1996; Bøggild et al., 2010). Recent studies have also shown links between sediment distribution and biological activity, indicative of feedback between microbial processes and albedo (e.g. Anesio et al., 2009; Uetake et al., 2010).

Due to the logistical demands of observing the ice sheet surface on foot, which is particularly problematic in the ablation zone where rivers, slush and crevasses make surface travel difficult, much of our present knowledge of its surface properties and processes has been gained through short 1-2 day field visits, automated data acquisition (primarily at automatic weather stations, some of which have now been operation for several years - for example those on the K-transect: http://www.projects.science.uu.nl/iceclimate/ aws/greenland.php) and satellite remote sensing. Consequently there are very few data sets comprising manual observations of seasonal changes in surface characteristics, and none on seasonal changes in biological activity on the ice 
sheet. Many more observations are needed to accurately estimate the contribution of observed biological activity to global chemical cycles, ideally leading to a method by which such activity can be monitored remotely.

In 2012 a field camp was established centrally in the ice sheet ablation zone at $1030 \mathrm{~m}$ elevation, $35 \mathrm{~km}$ from the western margin, with the aim of acquiring a continuous 10 -week time series of data relating to surface characteristics and processes. The camp was occupied continuously from 26 May to 10 August, covering most of the melt season. Resulting data on surface ablation, surface type and surface productivity (as quantified by biological oxygen demand (BOD) experiments) are compared with a satellite remote-sensing time series of surface albedo for the same location. Using these data sets, we identify the characteristics of physical and biological surface processes at the field site and assess the extent to which these can be quantified remotely in surface albedo retrievals. We finally examine in more detail the seasonal changes in surface productivity, which are presently unknown in Greenland. To our knowledge, this is the longest record of ground-based surface observations yet to be collected on the ice sheet.

\subsection{Ablation zone ice surface characteristics}

During the melt season, the ice sheet surface in the ablation zone displays a wide range of features commonly found on terrestrial glaciers, including crevasses, rivers, lakes, cryoconite holes and snow remnants. A variable amount of fine surface debris is also present, for example as dispersed particles, as a thin layer in cryoconite holes, or as thick deposits (Fig. 1). This fine debris, usually referred to as cryoconite, is mostly composed of fine mineral particles with a small $(<10 \%)$ organic matter content (Bayley, 1891; Hodson, 2010; Wientjes et al., 2011). Typical particle sizes are of order $10^{-5}$ to $10^{-4} \mathrm{~m}$ (data from several studies reported in Table 1 of Hodson et al., 2010). During the summer, debris causes some parts of the ablation zone to appear notably darker than the surrounding ice in satellite images (van de Wal and Oerlemans, 1994; Wientjes et al., 2011). These dark zones can be clearly observed each year during the melt season in true-colour MODIS AERONET imagery of west Greenland (http://lance-modis.eosdis.nasa.gov/ imagery/subsets/?project=aeronet\&subset=Kangerlussuaq). The lower albedo of the dark region in the ablation zone has previously been interpreted as arising from the accumulation of surface melt water (Oerlemans and Vugts, 1993; Knap and Oerlemans, 1996). Whether debris- or water-related, this zone of lower albedo has a direct impact on surface melt rates and therefore on ice sheet mass balance.

As a consequence of the variable surface characteristics and debris cover, the ice surface albedo can range widely, from $>80 \%$ (fresh snow) to typically $40-60 \%$ (bare ice) and as low as $10 \%$ for cryoconite debris (Knap and Oerlemans, 1996; Bøggild et al., 2010). However, bare ice containing
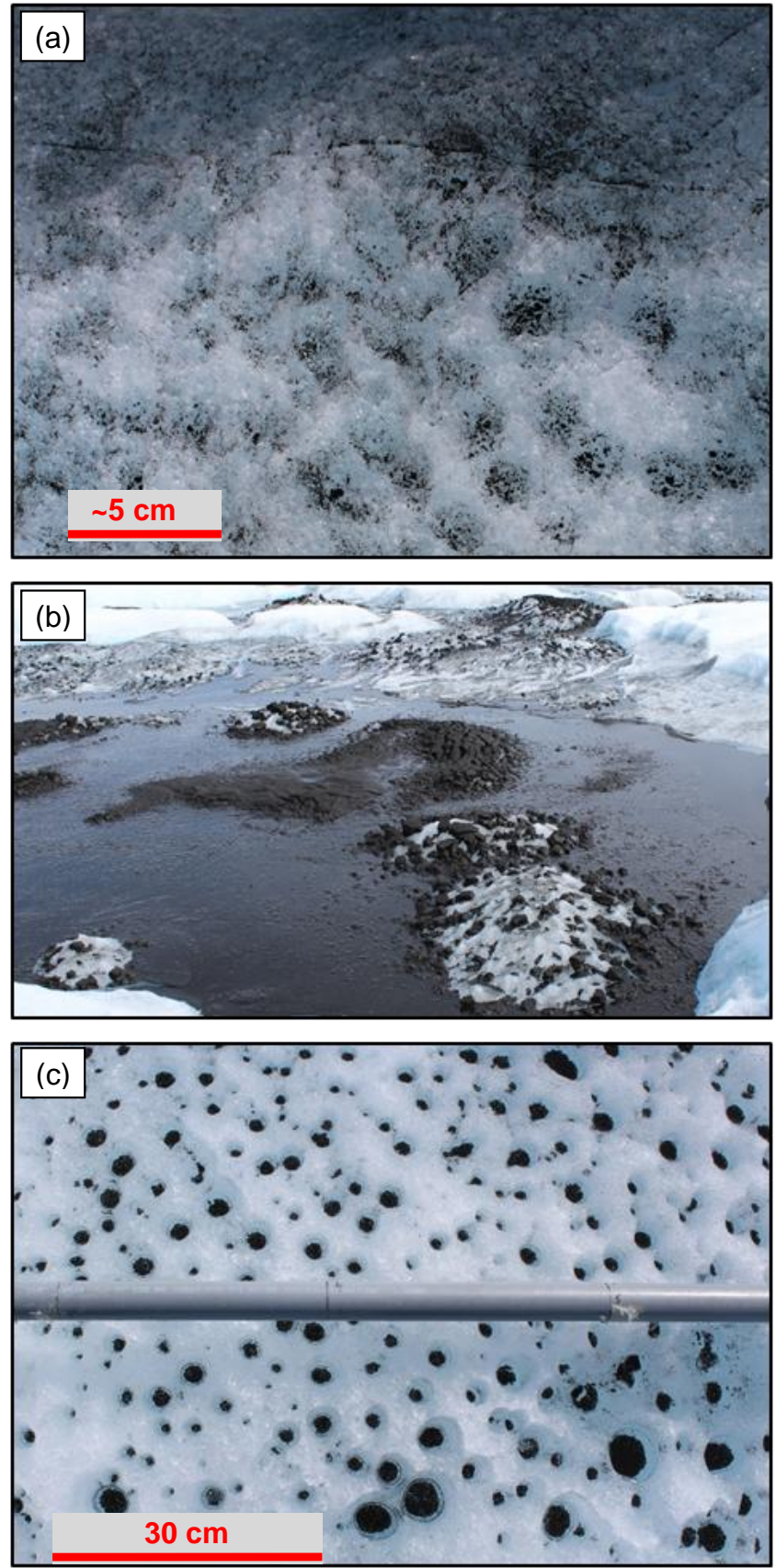

Figure 1. Debris on the ice sheet surface at approximately $67.0^{\circ} \mathrm{N}$, $49.3^{\circ} \mathrm{W}, 1030 \mathrm{~m}$, in the 2012 melt season. (a) Dispersed debris. The foreground shows debris released by the melting-out of cryoconite holes while the more uniform cover in the background is typical "dirty ice". The linear feature oriented right to left is a healed fracture. The image width at the surface is $\sim 50 \mathrm{~cm}$. (b) Thick deposits in a slowly draining lake bed, here reaching $\sim 6 \mathrm{~cm}$ thick. (c) Cryoconite holes. The plastic pole is marked at $30 \mathrm{~cm}$ intervals. These are relatively small cryoconite holes; some reach over $1 \mathrm{~m}$ in diameter. 


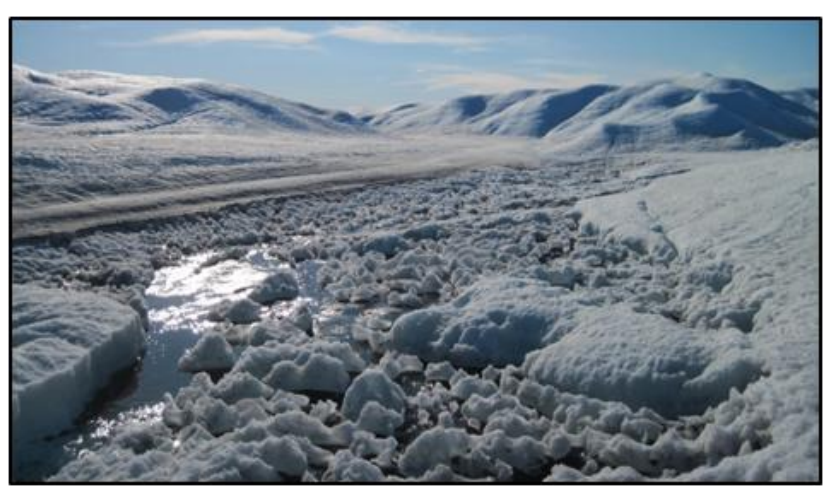

Figure 2. The ice sheet surface at $67.0^{\circ} \mathrm{N}, 50.0^{\circ} \mathrm{W}, 580 \mathrm{~m}(7 \mathrm{~km}$ from the margin), early in the melt season (10 June 2011). The foreground is a recently drained pond with cryoconite debris and "spikes" of clean ice that have melted much more slowly due to their higher albedo. The "hills" in the background have heights of $3-5 \mathrm{~m}$ and very low debris cover.

cryoconite holes has been found to have a higher albedo than bare ice with a lower mass loading of dispersed debris, because the depth of the cryoconite holes keeps the debris partially hidden at most incidence angles (Bøggild et al., 2010). Seasonal changes in albedo have been identified in the ablation zone, where a sharp then gradual decrease in albedo in the early melt season is associated with the melting of highly reflective seasonal snow and the subsequent increase in surface water and/or exposure of surface debris (Knap and Oerlemans, 1996; Stroeve et al., 2001; Wientjes et al., 2011). Although none of these studies has presented detailed time series lasting longer than a year, consistency between the different years and locations investigated suggests the reported seasonal patterns are widespread and persistent.

In addition to the different ice types and patchy debris cover, the ice surface is also characterised by its small-scale topography. For example, the variable action of surface melt leads to the formation of the "lumpy" topography in the lower ablation zone, with peak-to-peak height differences between valleys and ridges increasing down-glacier and reaching $5 \mathrm{~m}$ close to the margin in west Greenland (Fig. 2). This topography includes the characteristic "domes", "hummocks" and "gullies" described by Smeets and van den Broeke (2008) towards the end of the melt season at $67^{\circ} \mathrm{N}$. Development of these topographical features and the change from snow to bare ice lead to large spatial and seasonal changes in the aerodynamic roughness length of several orders of magnitude. This affects the sensible and latent heat fluxes into (or out of) the ice but has been rarely measured in the ablation zone (Duynkerke and van den Broeke, 1994; Smeets and van den Broeke, 2008). Remote sensing of surface roughness has been shown to be possible using a Multiangle Imaging SpectroRadiometer (MISR) in the Sermeq Kujalleq (Jacobshavn) region of west Greenland (Nolin et al., 2002; Nolin and Payne, 2007) but seasonal changes in roughness measured using this technique have not yet been reported. Roughness is not considered further in the present paper but should be addressed in future studies.

\subsection{Ablation zone ice surface biological processes}

The lack of any obvious plant or animal life on the ice sheet gives the impression that the surface is devoid of biological activity. However, studies of surface debris on the Greenland Ice Sheet have revealed the existence of active microbial communities including bacteria, cyanobacteria and green algae (Steinböck, 1936; Hodson et al., 2010; Stibal et al., 2012). Much of the activity was originally believed to be associated with the fine debris concentrated in a thin layer on the bottom of cryoconite holes (Anesio et al., 2009), but activity in algae present over much of the remaining surface in the ablation zone has recently been reported (Cook et al., 2012).

Cryoconite holes are widespread in the ablation zone of the Greenland Ice Sheet as well as in many other glaciated areas worldwide, and may form an important component of regional chemical cycles (e.g. Hodson et al., 2007; Anesio et al, 2009; Cook et al., 2012; Telling et al, 2012b). Since the Greenland Ice Sheet's melt zone has (potentially) a much greater surface area of microbial communities than that of any other terrestrial ice mass outside Antarctica, the role of the ice sheet's surface debris in the global carbon cycle has attracted increasing attention. Measurements of ecosystem productivity by in situ incubation experiments (Table 1) have revealed active communities in the few field sites visited on the ice sheet to date. Incubation experiments have now seen widespread use on many other glaciers, where similarly high levels of biological activity have been observed (Telling et al., 2010). The most detailed study in Greenland collected productivity measurements along a $70-\mathrm{km}$ transect across the ablation zone in west Greenland at $67^{\circ} \mathrm{N}$ (Stibal et al., 2012; Cook et al., 2012), close to the field site studied in the present paper. Stibal et al. (2012) found a peak in cryoconite hole carbon storage rate ( $22 \pm 4.8 \mu \mathrm{gC}$ day $^{-1}$ per unit mass of debris) at $11 \mathrm{~km}$ from the margin (761 ma.s.l.) and subsequent decrease to near zero by $65 \mathrm{~km}$ ( $1446 \mathrm{~m}$ a.s.l.). The most active part of the transect in terms of carbon storage rate per unit area was $\sim 7 \mathrm{mgC} \mathrm{m}^{-2} \mathrm{day}^{-1}$ at the ice margin (399 m a.s.l.) where debris cover is very high (Stibal et al., 2012). Interestingly, measurements of surface algae productivity on the debris-poor ice between holes suggested the carbon storage by surface algae might be considerably higher than the above figures for cryoconite holes (Yallop et al., 2012), but the different method $\left({ }^{14} \mathrm{C}\right.$ uptake; $1 \mathrm{~h}$ incubation rather than $24 \mathrm{~h}$ ) introduced considerable uncertainty in the estimates. Attempts have been made to calculate ice sheet-scale carbon fluxes from Greenland's cryoconite holes and surface algae by extrapolating existing data (Hodson, 2010; Cook, 2012); however, the great variability in carbon fluxes measured at different field sites (Table 1) and a lack of knowledge regard- 
Table 1. Cryoconite hole carbon flux measurements in Greenland.

\begin{tabular}{|c|c|c|c|}
\hline Source & Method & $\begin{array}{l}\text { Carbon storage rate } \\
\mu \mathrm{gC}[\mathrm{g} \text { or } \mathrm{L}]^{-1} \mathrm{~d}^{-1}\end{array}$ & Notes \\
\hline Anesio et al. (2009) & ${ }^{14} \mathrm{C}$ & $\begin{array}{l}\text { Water } 54 \pm 60 \\
\text { Sediments } 115 \pm 56\end{array}$ & $\begin{array}{l}\text { Frøya Glacier, east Greenland, } 74^{\circ} \mathrm{N} \text {, } \\
\text { date not specified }\end{array}$ \\
\hline Hodson et al. (2010) & $\begin{array}{l}\text { TDIC, } \\
\mathrm{O}_{2}\end{array}$ & $\begin{array}{l}\text { Sediments } \\
\text { Mean }-3.9^{2} \\
P: 12-30 \\
R: 4.8-29\end{array}$ & $\begin{array}{l}\text { South-west margin, } 67^{\circ} \mathrm{N}, \\
2-\mathrm{km} \text { transect at margin } \\
(\sim 2 \% \text { of melt zone }) \\
23-30 \text { August } 2008\end{array}$ \\
\hline $\begin{array}{l}\text { Stibal et al. (2012); } \\
\text { Cook et al. (2012) }\end{array}$ & TDIC & $\begin{array}{l}\text { Sediments } \\
\text { Mean: } 5.4^{3} \\
\text { Range from below detection } \\
\text { limit to } 22 \pm 4.8\end{array}$ & $\begin{array}{l}\text { South-west margin, } 67^{\circ} \mathrm{N}, \\
65-\mathrm{km} \text { transect with nine stations } \\
\text { from margin to slush zone, } \\
\text { August } 2010 .\end{array}$ \\
\hline
\end{tabular}

\footnotetext{
${ }^{1}$ Units $\mu \mathrm{gCg} \mathrm{g}^{-1} \mathrm{~d}^{-1}$ or $\mu \mathrm{gC} \mathrm{L} \mathrm{L}^{-1} \mathrm{~d}^{-1}$ represent the carbon flux per gram of dry sediment per day or the carbon flux per litre of water per day. ${ }^{2} \mathrm{Mean}$ NEP calculated from $\mathrm{O}_{2}$ and TDIC incubation experiments BI1 to BI5 reported in Table 2 of Hodson et al. (2010). ${ }^{3}$ Mean NEP of nine stations along the transect using results reported in their Table 3 .
}

ing seasonal variability requires many more measurements to be made before realistic extrapolation is possible.

In addition to its biogeochemical interest, biological activity in cryoconite debris can modify the characteristics of the debris itself, for example by generating dark organic material or by causing small grains to clump together into larger, less mobile particles. These processes alter the albedo of the cryoconite holes (Langford et al., 2010; Takeuchi, 2002), causing a corresponding reduction in the ice surface albedo, one of the key factors controlling ice sheet mass balance. We speculate that microbial processes will also affect the mobility of debris within the surface drainage system, and although this question remains open at present, it could be addressed using the time-lapse technique employed recently to observe cryoconite particle motion in Svalbard (Irvine-Fynn et al., 2011).

Given the importance of ice surface characteristics in controlling surface melt (and thus mass balance), and the increasing evidence for links between biological activity and surface characteristics, there is clearly a need to gain a better understanding of ice sheet surface processes in the ablation zone. In this paper, changes in the areal coverage and associated biological activity over most of a melt season are described for different surface types identified in the ablation zone of the western Greenland Ice Sheet at $67^{\circ} \mathrm{N}$. The resulting time series reveal the seasonal patterns in much greater detail than has been achieved in previous field studies.

\section{Methods}

Field data were collected during the 2012 summer melt season at $66.97^{\circ} \mathrm{N}, 49.27^{\circ} \mathrm{W}$, in the ablation zone of the ice sheet at $1030 \mathrm{~m}$ altitude and approximately $35 \mathrm{~km}$ from the western margin (Fig. 3). The field site is on the western edge of the "dark" band of the ablation zone identified by Wient-

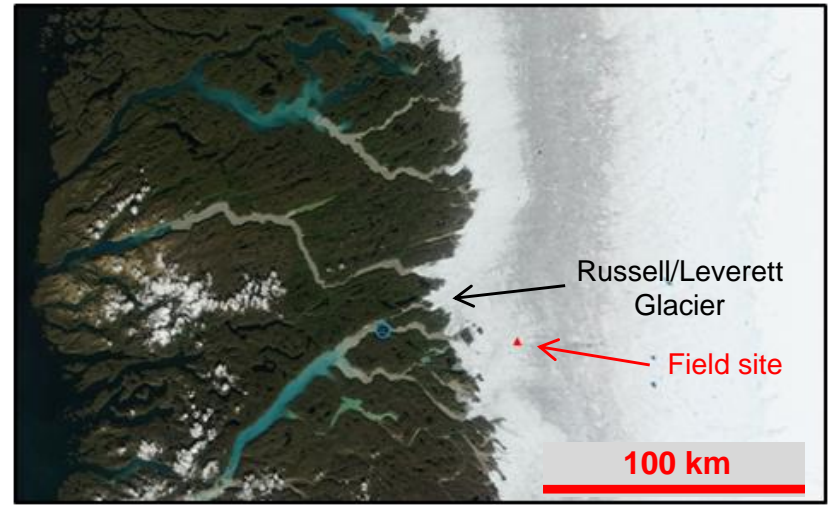

Figure 3. Field site location (red triangle) at $\sim 67^{\circ} \mathrm{N}$ in west Greenland, with the band of dark ice oriented north-south clearly visible in the ablation zone. The blue circle west of the field site marks Kangerlussuaq. The background image is a MODIS image acquired on 17 July 2012.

jes et al. (2011). Site locations for the surveys and incubation experiments (see below) were all located down-stream from, and on the opposite side of, a surface melt water stream passing adjacent to the field camp, to minimise any interference or contamination from human activity.

\subsection{Surface characteristics and ablation}

Daily ice ablation was recorded by measuring the distance between the ice surface and the tops of five $40 \mathrm{~cm}$ plastic poles installed in holes drilled $50-100 \mathrm{~cm}$ into the ice. Installing the stakes into the ice below the surface avoided the lateral melting that normally occurs around poles left protruding from the ice. Stakes were arranged in a "+" shape with four outer stakes and one in the centre, at $\sim 2 \mathrm{~m} \mathrm{spac}$ ing. The ice surface was often very rough, so for consistency 

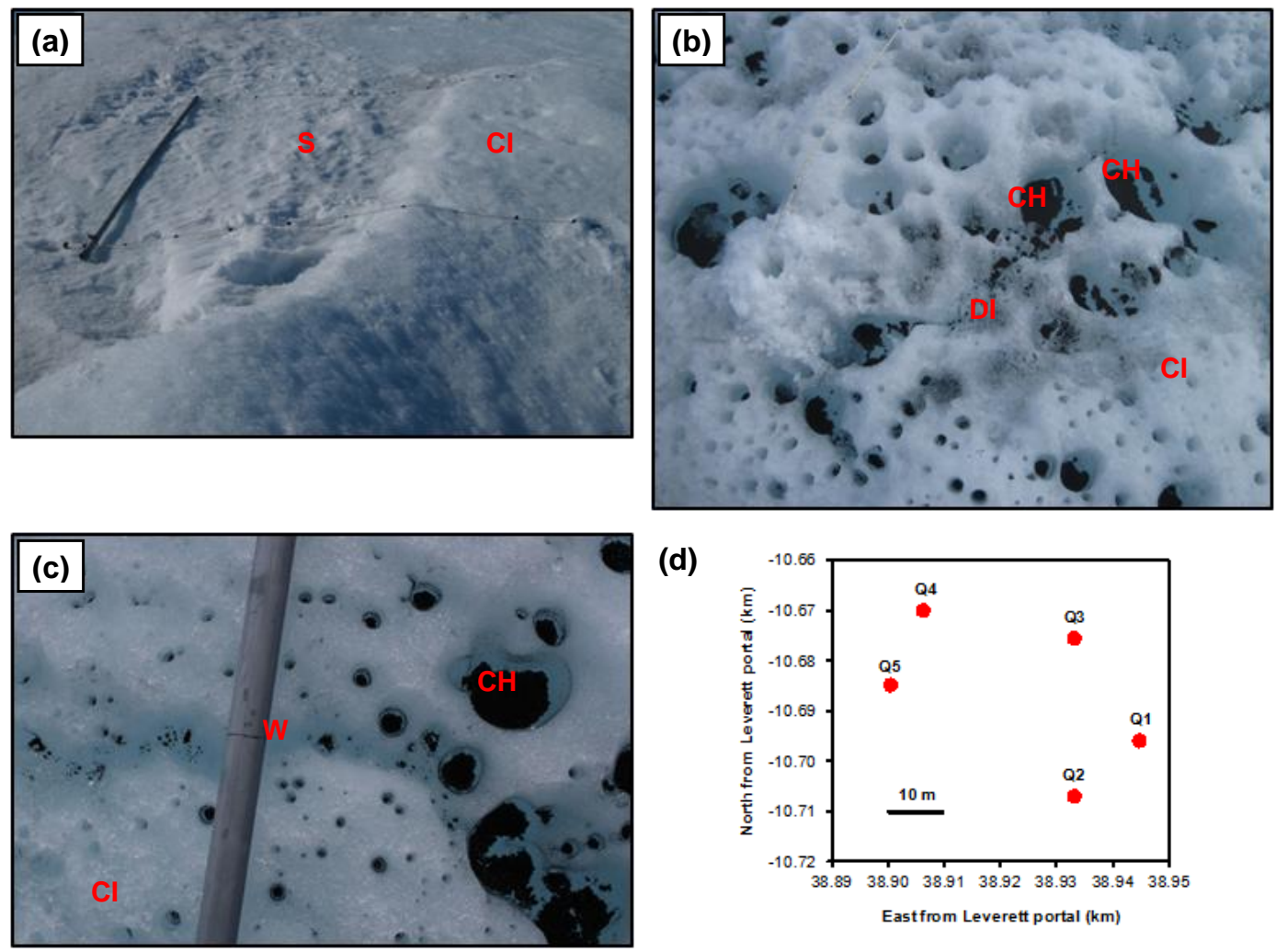

(d)

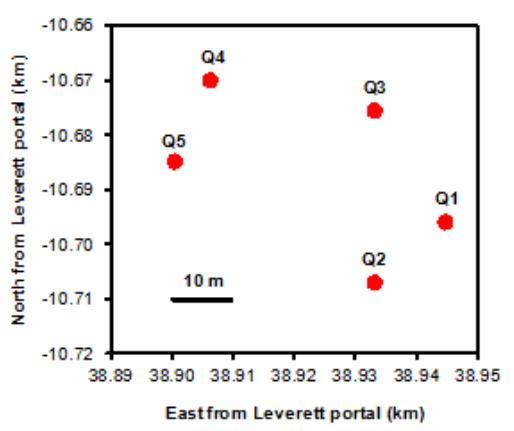

Figure 4. (a) Q2, 1 June 2012, showing the quadrat ropes and pole. Surface cover is $55 \%$ snow (S) and $45 \%$ clean ice (CI). (b) Lower left corner of Q4, 13 July 2012, with clean ice (CI), dirty ice (DI) and cryoconite holes (CH; Note that CS incubations sampled both the sediment and overlying water from these holes; CW incubations sampled only the water). (c) Q4 on 29 July, with a very small melt water channel linking cryoconite holes under the mark on the pole. (d) Locations of quadrats on 1 June 2012, co-ordinates are relative to the portal from which melt water draining from the field site emerges at the ice margin.

each measurement was taken to be the vertical distance between the stake top and a $25 \mathrm{~cm}$ hacksaw blade laid centrally across the top of the hole in an east-west orientation. The initial surface slope at the site was flat (less than $10^{\circ}$ ), but by August the site had become a lump with the central and northern stakes on its flat top and the eastern, southern and western stakes on sides sloping outwards at $10-20^{\circ}$. Stakes were re-drilled before the stake had started to protrude from the hole. This method yields ablation expressed as an elevation change, rather than the more commonly encountered unit of $\mathrm{mm}$ water equivalent ( $\mathrm{mm}$ w.e.). Conversion to $\mathrm{mm}$ w.e. from measured elevation change requires the densities of water and ice. In practice the density of ice close to the surface is very difficult to measure owing to the porous nature of the melt crust which has a density much lower than that of solid glacier ice. If this crust were to maintain a constant thickness, change in surface height would still yield ablation in mm w.e.; however, the melt crust characteristics (e.g. thickness, density) were very variable, and therefore we have not attempted to make this conversion.

Surface characteristics were monitored frequently from 1 June to 11 August (total 18 surveys) in five $2.7 \times 2.7 \mathrm{~m}$ quadrats situated within a region of roughly $60 \times 40 \mathrm{~m}$ (Fig. 4a and d). Each quadrat comprised a $10 \times 10$ grid with $30 \mathrm{~cm}$ spacing. Quadrat locations were marked by drilling $\sim 50 \mathrm{~cm}$ deep holes in the ice at each corner of a $3 \times 3 \mathrm{~m}$ square, to ensure the same area of ice was surveyed each time. To carry out a survey, two nylon ropes (both marked with the positions of the hole edges and then at $30 \mathrm{~cm}$ intervals) were laid out in parallel between each pair of holes. The ropes were kept tight by attaching steel weights that could hang freely in the drilled holes. A rigid $3 \mathrm{~m}$ pole, also marked at $30 \mathrm{~cm}$ intervals, was laid between the first pair of markers on the ropes. The surface type was recorded immediately in front of each mark along the pole, before moving the pole to the next pair of rope markers and recording the second row of surface types, and so on. Six surface types were present at the field site, of which five types were recorded in the quadrats (Table 2; Fig. 4). All surveys were carried out by the same pair of observers, to ensure consistency in the classification.

From a biological aspect, it would have been preferable to distinguish between superimposed ice and englacial ice (here both classified as CI) since they may well contain different abundances and/or species of micro-organisms. In practice it 
Table 2. List of surface types identified at the field site. All except Type F were present in the quadrat surveys.

\begin{tabular}{lll}
\hline Surface Type & Code & Description \\
\hline Snow & S & $\begin{array}{l}\text { Seasonal snow cover, including a coarse-grained granular material that is probably rotting } \\
\text { superimposed ice (Fig. 4a) }\end{array}$ \\
Water & W & $\begin{array}{l}\text { Surface water that is not covering cryoconite debris (Fig. 4c) } \\
\text { Clean ice }\end{array}$ \\
$\begin{array}{l}\text { Dirty ice } \\
\text { Cryoconite hole }\end{array}$ & DI & Englacial ice with no visible debris (Fig. 4a, b, c) \\
Fractures, moulins & F & $\begin{array}{l}\text { Water-filled holes with a layer of debris in the bottom (Figs. 1c, 4b, c) } \\
\text { Open fractures, crevasses and moulins were all present close to the field site but were not } \\
\text { recorded in the quadrat surveys }\end{array}$ \\
\hline
\end{tabular}

would have been difficult to confidently classify the ice surface in the field and in some cases they may even be mixed (for example, in a layer $\sim 10 \mathrm{~cm}$ thick where spring snow melt has penetrated the previous summer's permeable melt crust and then refrozen). Sometimes there were clues in the shape of the crystal remnants but classification would nevertheless be uncertain and subjective. Therefore, we do not make the distinction between these ice types.

\subsection{Productivity (biological oxygen demand)}

Net ecosystem production (NEP) and respiration were quantified within each of the different surface environments recorded in the quadrat surveys, at approximately weekly intervals, by measuring the rate of $\mathrm{O}_{2}$ production in samples collected from the ice surface. The method is described in detail by Telling et al. (2010). One sample was collected for each surface type present, and divided into six glass $250 \mathrm{~mL}$ biological oxygen demand (BOD) bottles. Ice samples were melted before pouring into the BOD bottles, by collecting the ice in a Whirl-pak bag and immersing the bag in lukewarm water. These melting samples were left in a black plastic box, typically for 2-3h, until completely melted (partially melted samples were not used). For samples representing cryoconite holes, debris from the base of the hole was collected using a $100 \mathrm{~mL}$ syringe fitted with a $\sim 20 \mathrm{~cm}$ plastic tube, and the area of debris removed from the hole was selected to match the area of the BOD bottle base (Fig. 5a). This ensured that the debris thickness in the bottle was representative of that in the hole. These bottles were then filled with water collected from the same hole as the debris. The debris typically settled out onto the base of the bottle within $30 \mathrm{~s}$.

The temperature and dissolved oxygen content of the water in each BOD bottle were measured using a PreSens Fibox3 fibre-optic oxygen meter (manufacturer's stated accuracy: $\pm 1 \%$ ), and the bottle was then immediately sealed with a glass stopper. Bottles were checked carefully to ensure no air bubbles were present. Three out of the six bottles for each sample type were wrapped in foil to eliminate light (therefore measuring respiration only); the other three remained unwrapped to allow photosynthesis as well as respiration (to

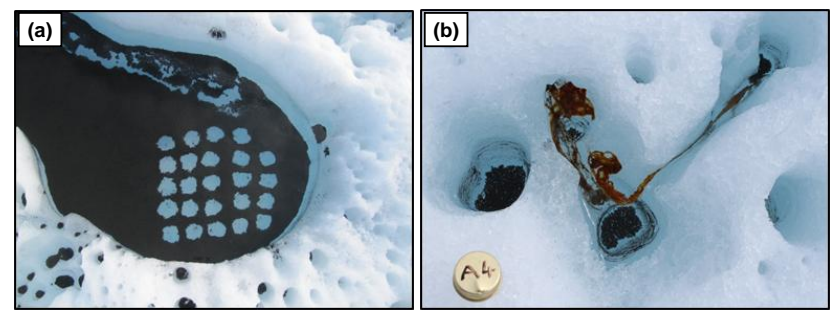

Figure 5. (a) Sample collection for the cryoconite water plus sediment incubation (13 July) left 24 round spaces, each about the diameter of the BOD bottle $(\sim 65 \mathrm{~mm})$. (b) Orange-green material sampled for the 4th and 9th July incubations. The lid diameter is $27 \mathrm{~mm}$.

measure NEP). All bottles were placed in a cryoconite hole sufficiently deep to ensure complete immersion, in order to replicate typical light and temperature conditions as well as to prevent the bottle freezing and cracking. After $24 \pm 1 \mathrm{~h}$, the bottles were recovered and the dissolved oxygen content and temperature were re-measured.

In addition to these standard weekly incubation experiments, we carried out four additional experiments to better characterise temporal and spatial variability and errors in NEP rates, as follows. (1) To better quantify the variance in the four common environments (water, clean ice, dirty ice, cryoconite hole) we carried out additional incubations with 12 light and 12 dark replicates of just one sample type. (2) Temporal variability in cryoconite hole productivity within the $24 \mathrm{~h}$ incubation time was measured from 4-5 August by filling 32 bottles (16 light, 16 dark) with cryoconite hole debris and water, then recovering sets of bottles at $3 \mathrm{~h}$ intervals for $24 \mathrm{~h}$. (3) Spatial variability and effects of cryoconite hole diameter were investigated on 6-7 August by choosing five sites and incubating light/dark pairs of samples from three holes of varying size (nominally "small", "medium" and "large") at each site. (4) Two standard incubations (4 and 9 July) also included samples of orange-green material (Fig. 5b) sampled from the former bed of a shrinking lake $\left(66.97^{\circ} \mathrm{N}, 49.21^{\circ} \mathrm{W} ; 3 \mathrm{~km}\right.$ east of the main field site). This material was only observed at one location, in a strip a 
few tens of metres wide extending for less than $500 \mathrm{~m}$ along the lake edge.

The rate of oxygen production in the BOD bottles, expressed in $\mathrm{mg} \mathrm{L}^{-1} \mathrm{~h}^{-1}$, is equal to the difference between the start and end point dissolved oxygen concentrations, divided by the incubation time. In this experiment, two rates of oxygen production were measured for each sample type: $\Delta \mathrm{O}_{2}^{\text {(light) }} / \Delta t$ and $\Delta \mathrm{O}_{2}^{(\text {dark })} / \Delta t$ for the light and dark bottles, respectively. We assume that respiration rates were independent of light conditions and therefore the same in the light and dark bottles. The rate of oxygen production by photosynthesis in the light bottles, representing that in the original environment, is therefore $P=\left(\Delta \mathrm{O}_{2}^{\text {(light) }}-\Delta \mathrm{O}_{2}^{(\text {dark })}\right) / \Delta t$.

To convert oxygen production into carbon storage, we assume photosynthesis can be represented as

$n \mathrm{CO}_{2}+n \mathrm{H}_{2} \mathrm{O} \rightarrow\left(\mathrm{CH}_{2} \mathrm{O}\right)_{n}+n \mathrm{O}_{2}$.

Respiration is taken to be the reverse reaction. In photosynthesis, this equation predicts that $n$ moles of $\mathrm{CO}_{2}$ are stored for each $n$ moles of $\mathrm{O}_{2}$ released. This assumption of a $1: 1$ stoichiometric ratio has been adopted in previous studies of cryoconite holes (Hodson et al., 2007, 2010; Anesio et al., 2009) but may not be exact: for example in Svalbard, Telling et al. (2010) found 1.24 \pm 0.20 moles of $\mathrm{O}_{2}$ were released for each mole of $\mathrm{CO}_{2}$ consumed during photosynthesis, while $0.80 \pm 0.17$ moles of $\mathrm{CO}_{2}$ were released for each mole of $\mathrm{O}_{2}$ consumed during respiration. Neglecting this uncertainty given the error bounds on the above ratios, a $1: 1$ molar ratio will yield $1.375 \mathrm{~g}$ of $\mathrm{CO}_{2}$ (or $0.375 \mathrm{~g}$ of $\mathrm{C}$ ) consumed per $1 \mathrm{~g}$ of $\mathrm{O}_{2}$ released.

Carbon storage rates in the BOD bottles are more useful after conversion to a surface flux (e.g. $\mathrm{mgC} \mathrm{m}^{-2} \mathrm{~d}^{-1}$ ) for each sample type. To achieve this we required the bottle volume $V_{\mathrm{B}}$, bottle radius $R_{\mathrm{B}}$, sample thickness (for ice samples) $H_{\mathrm{S}}$, incubation duration $T$, water density $\rho_{\mathrm{W}}$ and sample density $\rho_{\mathrm{S}}$. For water and cryoconite hole samples (CW, CS), the area of ice sheet $A_{\mathrm{S}}$ sampled to fill the bottle is $A_{\mathrm{S}}=\pi R_{\mathrm{B}}^{2}$. For ice samples, $A_{\mathrm{S}}=V_{\mathrm{B}} \rho_{\mathrm{W}} / H_{\mathrm{S}} \rho_{\mathrm{S}}$. The $\mathrm{C}$ flux $F_{\mathrm{C}, X}$ from each ice type $X$ is then $F_{\mathrm{C}, X}=$ $\Delta \mathrm{O}_{2}^{\text {(light) }} \times 0.375 V_{\mathrm{B}} /\left(A_{\mathrm{S}} T\right)$ and the total carbon flux into the surface at the field site is the sum of $A_{X} F_{\mathrm{C}, X}$ over all the ice types $X$, weighted for their respective fractional areas $A_{X}$ as determined in the quadrat surveys. Parameter values were as follows: $V_{\mathrm{B}}=250 \mathrm{~mL}, R_{\mathrm{B}}=32 \mathrm{~mm}, H_{\mathrm{S}} \approx 30 \mathrm{~mm}$, $\rho_{\mathrm{S}}=900 \mathrm{~kg} \mathrm{~m}^{-3}$ (ice), $\rho_{\mathrm{S}}=300 \mathrm{~kg} \mathrm{~m}^{-3}$ (snow), $\rho_{\mathrm{W}}=1000$ $\mathrm{kg} \mathrm{m}^{-3}$. Quadrat surveys and BOD experiments did not always coincide, so both data sets were linearly interpolated to daily resolution to allow calculation of daily values for the product $A_{X} F_{\mathrm{C}, X}$ and for the net $\mathrm{C}$ flux.

\subsection{Surface albedo}

A surface broadband albedo product (AVHRR-SAL, CM59), derived from data collected by the AVHRR (Advanced Very High Resolution Radiometer) instrument onboard the NOAA polar orbiting MetOp platforms, is available from the Climate Monitoring Satellite Application Facility (CM SAF) for the Arctic region. Monthly and weekly averaged products are available on a $15 \times 15 \mathrm{~km}$ grid, and an instantaneous product on a $1 \times 1 \mathrm{~km}$ grid. We use the latter product here because of its higher resolution. A summary of the product follows; for a full description see Karlsson et al. (2012). Albedo is calculated for each AVHHR-imaged pixel $\left(\sim 1.1 \mathrm{~km}^{2}\right)$, using satellite and sun viewing geometry and recorded top-ofatmosphere reflectances. In addition, land cover data, a cloud mask, surface pressure and water vapour from Deutsche Wetter Dienst are used. Cloud shadow effects are reduced by the removal of not only all cloud pixels, but also of all pixels neighbouring a cloud pixel. A topographical correction is applied to the observed reflectances and used to assign a reflectance to hidden slopes. Water vapour and surface pressure data from Deutsche Wetter Dienst are used under the assumption of constant ozone content and aerosol optical depth of the atmosphere to convert top-of-atmosphere reflectances to surface reflectances. These surface reflectances are used to calculate black sky surface albedo, following SchaepmanStrub et al. (2006) for radiation of 0.25 to $2.5 \mu \mathrm{m}$; this is almost equivalent to full broadband surface albedo since shortwave infrared contributions to the full broadband albedo are generally very small, and we treat it here as equivalent. Distance-weighted interpolation was used to calculate the surface broadband albedo for the field site location from the $1 \times 1 \mathrm{~km}$ grid in which the CM SAF product is provided.

Only those images where all four closest pixels were assigned an albedo value were retained for further analysis. We also restricted the image acquisition time to within $6 \mathrm{~h}$ of local solar noon to avoid images acquired at high zenith angles. Finally, remaining images were grouped into daily bins before calculating the mean and standard deviation albedo value for each day.

\subsection{Meteorological data}

Meteorological data were obtained from an automatic weather station installed on the nearby K-transect (Greuell et al., 2001). These data were kindly provided by the Institute for Marine and Atmospheric Sciences, Utrecht University (IMAU). Further details of the field sites and instrumentation can be found at http://www.projects.science.uu. nl/iceclimate/aws/home.html. There are several AWSs (Automatic Weather Stations) on the transect, the closest of which in terms of both location and altitude is S6 $\left(67^{\circ} 04 \mathrm{~N}\right.$, $49^{\circ} 23 \mathrm{~W}, 1030 \mathrm{~m} ; 11 \mathrm{~km}$ NNW from our field site). The measurements of most importance to this paper are the air temperature and relative humidity (both at $2 \mathrm{~m}$ above the 

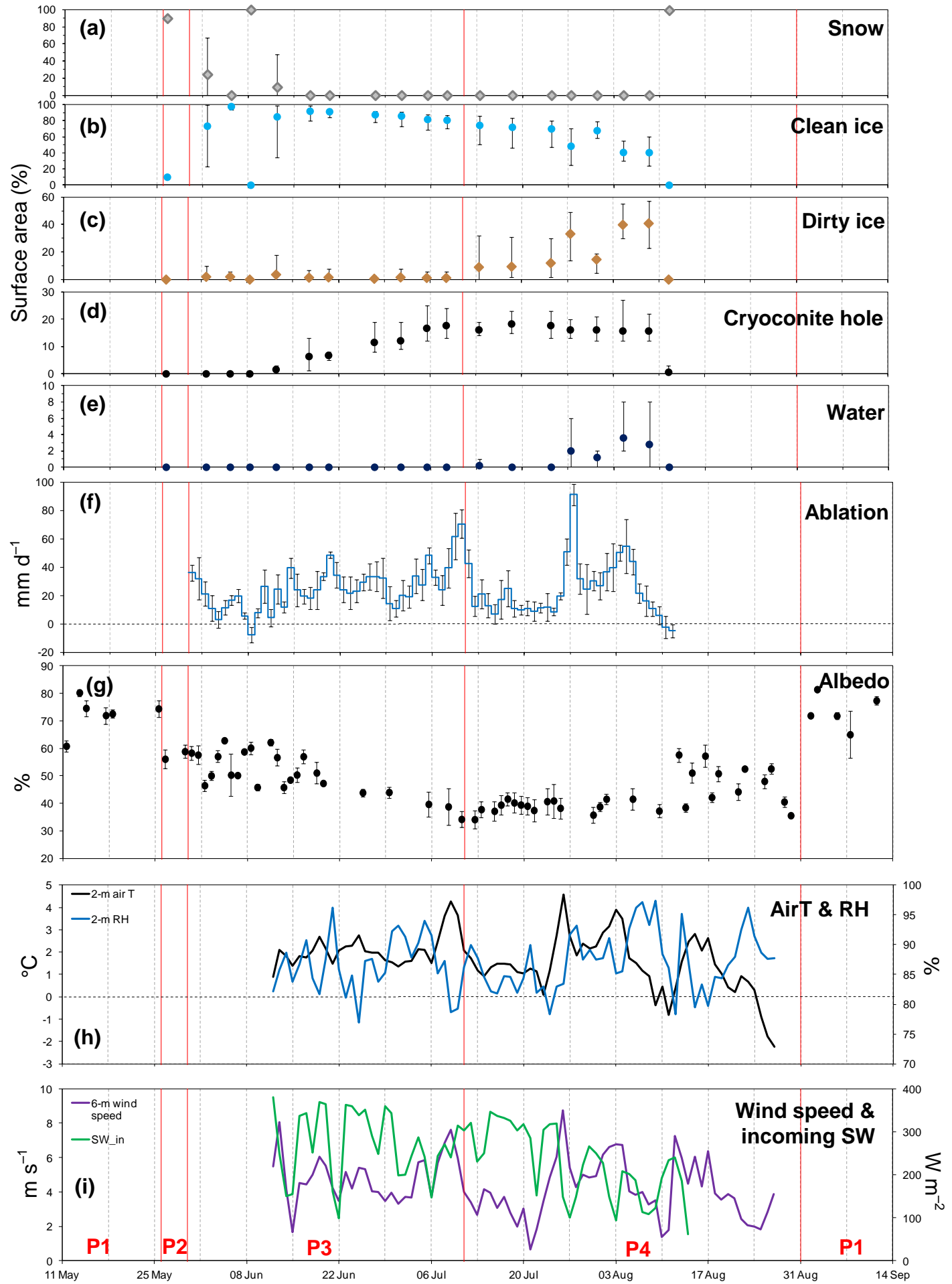

Figure 6. Percentage surface area (SA) covered by (a) snow, (b) clean ice, (c) dirty ice, (d) cryoconite holes and (e) water. Error bars are the range observed in five quadrats. (f) Daily ablation rate showing mean of five measurements (blue line); error bars are $\pm 1 \sigma$. (g) Daily mean AVHRR-derived surface albedo $\pm 1 \sigma$. Vertical red lines are approximate boundaries between periods P1 and P4 (see text). (h-i) Daily averages of $2 \mathrm{~m}$ air temperature, relative humidity, $6 \mathrm{~m}$ wind speed and incoming short-wave radiation intensity at AWS S6 located $11 \mathrm{~km}$ from our field site. 
surface), wind speed (6 $\mathrm{m}$ above the surface) and incoming short-wave radiation. Each of these are logged at $30 \mathrm{~min}$ intervals.

To assess whether photosynthetic activity is dependent on light intensity, we used the AWS S6 incoming shortwave radiation data recorded by a Kipp and Zonen CNR1 radiometer (305 to $2800 \mathrm{~nm}$ sensitivity; accuracy $10 \%$ ). The SW data for S6 are missing before 12 June and were therefore estimated using data from AWS S5. Estimates were based on linear regression between SW data from the two AWSs S5 and S6 for the period 12 June-15 August, which yielded $\mathrm{SW}_{\mathrm{S} 6}=0.984 \mathrm{SW}_{\mathrm{S} 5}+15.17\left[\mathrm{~W} \mathrm{~m}^{-2}\right] ; r^{2}=0.89 ; n=3088$. This provided a better fit than that using data from AWS S9 $\left(r^{2}=0.71\right)$.

\section{Results}

Time series of ice surface types, ablation rate, albedo and BOD are plotted in Figs. 6 and 7. Mean $\pm 1 \sigma$ ablation during the observation period (averaged over the five stakes) was $25 \pm 2 \mathrm{~mm} \mathrm{~d}^{-1}$; a peak of $91 \pm 7 \mathrm{~mm} \mathrm{~d}^{-1}$ occurred on 27 July. Total ablation from 29 May to 11 August was $1.8 \mathrm{~m}$ (average), ranging from 1.6 to $2.0 \mathrm{~m}$. Accumulation (negative ablation) was only recorded on 8 June, and 10-11 August, following fresh snow falls.

\subsection{Surface characteristics}

A total of 18 quadrat surveys were completed between 1 June and 11 August. The extensive snow cover present on arrival at the site (estimated at $90 \%$ cover on 26 May) rapidly melted to slush during heavy rain on 27 May and had reduced to $24 \%$ when the first quadrat survey was completed on 1 June (Fig. 6a). No snow was left in the quadrats by 5 June, although numerous, deep channels filled with slush and snow were still common close to the field site after this time. The retreating snow uncovered a smooth, mostly debris-free ice surface that lacked any evidence of the cryoconite holes and debris which were observed to be widespread at this site in late August 2011. Hence, we assume that this upper ice surface layer was composed of superimposed ice formed by the refreezing of percolating snow melt in spring/early summer. After a brief period of fresh snowfall on 7-8 June, the 2011 ice surface became increasingly exposed and cryoconite holes were first observed in the quadrats on 13 June (Fig. 6d). The area covered by cryoconite holes gradually increased, reaching $\sim 18 \%$ on 8 July, before remaining steady at this percentage coverage until the final survey on $11 \mathrm{Au}-$ gust, when they were mostly hidden by fresh snow.

Very little dirty ice (DI) was present early in the season: areal coverage remained below $4 \%$ until 13 July (Fig. 6c), when a period of warm, cloudy and very windy weather resulted in rapid surface melting (reaching $71 \pm 10 \mathrm{~mm} \mathrm{~d}^{-1}$ on 10 July). Many of the small, shallow cryoconite holes melted

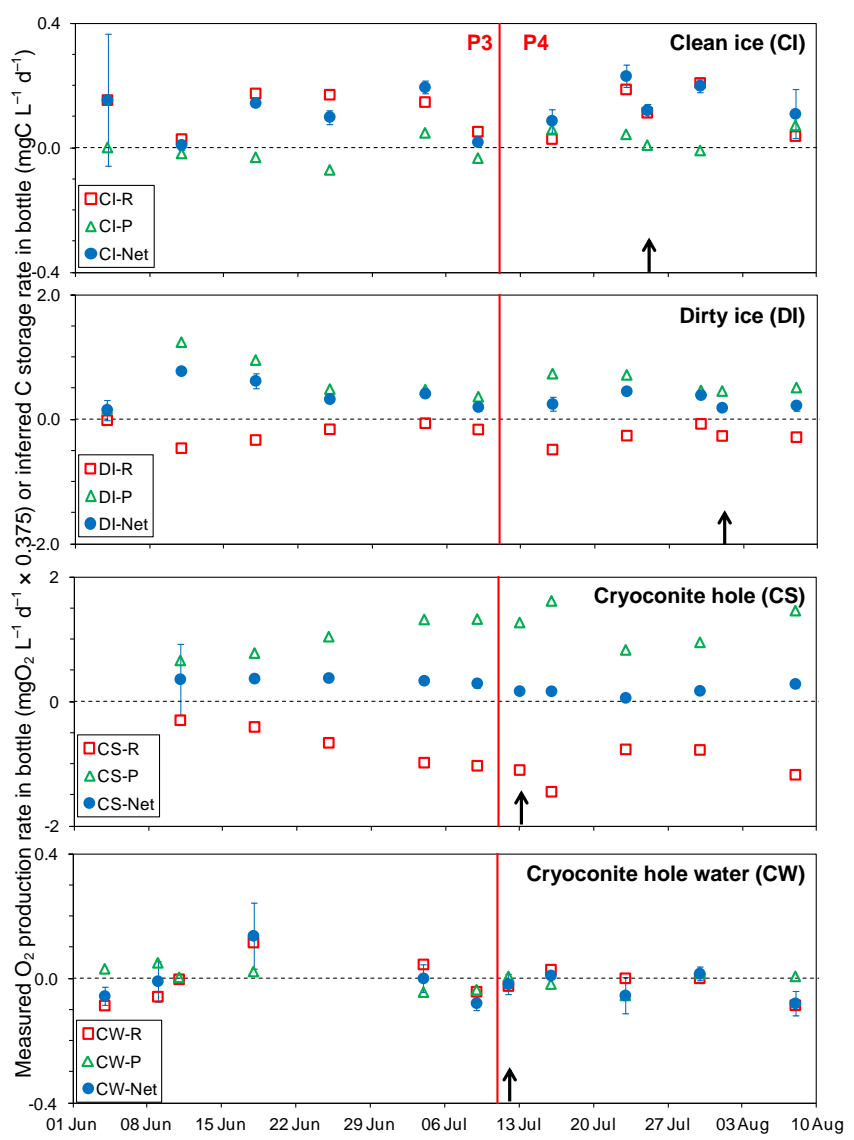

Figure 7. Seasonal variation in productivity as measured by $\mathrm{O}_{2}$ production or inferred $\mathrm{C}$ storage in the BOD incubation experiments for (a) clean ice; (b) dirty ice; (c) cryoconite holes (cryoconite debris plus water); and (d) cryoconite hole water. Symbols are respiration ( $\mathrm{R}$; red squares) and net carbon storage (N; blue circles), both measured directly, and inferred photosynthesis (P; green triangles) calculated by $\mathrm{P}=\mathrm{N}-\mathrm{R}$. Note the different scales on the vertical axes. Arrows mark the times of 24-bottle single-sample-type variance experiments (see Fig. 10) and red lines mark the approximate change from period $\mathrm{P} 3$ to $\mathrm{P} 4$ (see text)

out completely in this period, and the resulting dispersal of their debris lead to the first notable increase in DI cover between 8 and 13 July. This is illustrated by the patchy debris in Fig. 1a. DI coverage became more spatially variable after this time, as indicated by the wide error bars in Fig. 6c. A further increase between 24 and 27 July coincided with a shorter but more intense melt event. Excavating dirty ice surfaces with an ice axe showed that the debris was confined to the upper melt crust, consistent with findings in a field study of the ice surface in northeast Greenland (Bøggild et al., 2010).

Surface water outside of cryoconite holes covered very little of the quadrat surfaces (maximum 3.6\%; 4 August; Fig. 6e). Although many streams and lakes/ponds exist in this part of the ice sheet, the wide spacing of narrow channels results in a low percentage surface area. Much of the local 
Table 3. Summary of productivity data for the regular ( weekly) incubation experiments, presented as mean $\pm 1 \sigma$ of carbon storage rates in $n$ incubation experiments. $P, R$ and net are results for inferred photosynthesis only, inferred respiration only, and both processes combined. $\mathrm{C}$ storage is the carbon storage rate in the bottle. $\mathrm{C}$ flux is the seasonal mean of $\mathrm{C}$ storage when converted to carbon flux, based on the surface area sampled to fill the bottle; C flux (total) is the C flux weighted by the fractional surface area of that type, with [5, 95\%] percentiles of 66 interpolated daily values. Observation periods for productivity were 4 June-8 August 2012 except snow (9 June only) and orange-green material (4 and 9 July only).

\begin{tabular}{|c|c|c|c|c|c|}
\hline Surface type & $n$ & & $\begin{array}{l}\text { C storage rate } \\
\mathrm{mgC} \mathrm{L}^{-1} \mathrm{~d}^{-1}\end{array}$ & $\begin{array}{c}\mathrm{C} \text { flux } \\
\mathrm{mgC}^{-2} \mathrm{~d}^{-1}\end{array}$ & $\begin{array}{l}\text { C flux (total) } \\
\mathrm{mgC} \mathrm{m}^{-2} \mathrm{~d}^{-1}\end{array}$ \\
\hline $\begin{array}{l}\text { Clean ice } \\
(\mathrm{CI})\end{array}$ & 10 & $\begin{array}{l}\text { Net } \\
P \\
R\end{array}$ & $\begin{array}{c}0.13 \pm 0.08 \\
0.002 \pm 0.048 \\
0.12 \pm 0.08\end{array}$ & $5.7 \pm 3.4$ & $2.4[0.30,4.1]$ \\
\hline $\begin{array}{l}\text { Dirty ice } \\
\text { (DI) }\end{array}$ & 10 & $\begin{array}{l}\text { Net } \\
P \\
R\end{array}$ & $\begin{array}{c}0.40 \pm 0.20 \\
0.64 \pm 0.31 \\
-0.24 \pm 0.17\end{array}$ & $18 \pm 9.0$ & $0.89[0.07,3.0]$ \\
\hline $\begin{array}{l}\text { Cryoconite hole } \\
\text { water } \\
(\mathrm{CW})\end{array}$ & 10 & $\begin{array}{l}\text { Net } \\
P \\
R\end{array}$ & $\begin{array}{c}0.004 \pm 0.010 \\
-0.010 \pm 0.035 \\
0.014 \pm 0.16\end{array}$ & $0.5 \pm 8.1$ & $-0.015[-0.16,0.001]$ \\
\hline $\begin{array}{l}\text { Cryoconite hole } \\
\text { water \& debris } \\
\text { (CS) }\end{array}$ & 8 & $\begin{array}{l}\text { Net } \\
P \\
R\end{array}$ & $\begin{array}{c}0.24 \pm 0.11 \\
1.0 \pm 0.33 \\
-0.76 \pm 0.47\end{array}$ & $30 \pm 14$ & $2.5[0,4.7]$ \\
\hline $\begin{array}{l}\text { Snow } \\
(\mathrm{SN})\end{array}$ & 1 & $\begin{array}{l}\mathrm{Net} \\
P \\
R\end{array}$ & $\begin{array}{l}-0.025 \pm 0.027 \\
-0.003 \pm 0.035 \\
-0.022 \pm 0.022\end{array}$ & $-0.23 \pm 0.24$ & $-0.010[-0.060,0]$ \\
\hline $\begin{array}{l}\text { Orange-green } \\
\text { material } \\
(\mathrm{OG})\end{array}$ & 2 & $\begin{array}{l}\mathrm{Net} \\
P \\
R\end{array}$ & $\begin{array}{c}0.002 \pm 0.064 \\
1.7 \pm 0.22 \\
-1.7 \pm 0.3\end{array}$ & $0.3 \pm 8.1$ & - \\
\hline
\end{tabular}

(<10 m-scale) melt water drainage appeared to flow through a permeable melt crust, which reached several $\mathrm{cm}$ thickness after long periods of sunny weather, before eventually joining the larger, visible drainage channels. The melt crust is formed by the penetration of solar radiation into the ice, which permits melting within a relatively thick surface layer and creates a wide variety of ice formations (Fig. 8). Exceptions to this pattern were periods of warm, windy weather (Fig. 6), when the surface melt crust was quickly stripped away and replaced by a hard, slippery and impermeable surface; these times correspond to the higher (but still small) incidence of surface water in the quadrats in late July and early August.

The ice surface at the field site was initially quite smooth, mostly snow with a few ice patches and lumps of less than $50 \mathrm{~cm}$ in height (similar to the photo in Fig. 9a, taken on 1 June). As melt progressed, the surface became increasingly uneven with a mix of bumps up to approximately $150 \mathrm{~cm}$ high and melt channels up to $3 \mathrm{~m}$ deep (similar to the photo in Fig. 9b, taken on 31 July).

\subsection{Productivity}

In total, 17 incubation experiments were carried out between 4 June and 8 August (Fig. 7; Table 3). Results averaged over the regular weekly experiments in the light bottles showed changes in $\mathrm{O}_{2}$ significantly different from zero $(p<0.05)$ in

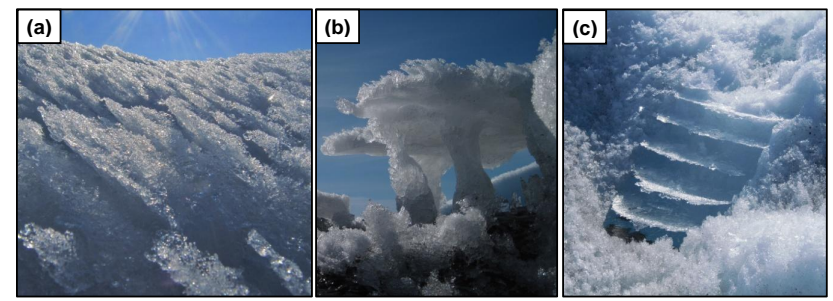

Figure 8. Ice formations arising from radiative melt. (a) "Feathers" ca. 5-10 cm long, overlying a permeable melt crust a further several centimetres thick. These needed several days of cold, sunny weather to form. (b) "Mushrooms", approximately $20 \mathrm{~cm}$ diameter and $15 \mathrm{~cm}$ tall, which we believe formed from remnants of the previous year's cryoconite holes. (c) "Stacks" of cryoconite hole lids, formed when the water in the cryoconite hole freezes overnight. Each lid represents the water level that night, then the water level drops during the day as the surrounding ice surface ablates.

CI, DI and CS, and no significant change in CW, SN and OG. Significant inferred photosynthesis and respiration, as estimated from the combined light and dark bottle results (see Sect. 2.2), was found in DI and CS as well as in the orangegreen material (OG) collected from the former lake bed $3 \mathrm{~km}$ from the site (Table 3 ). In each of these three sample types, light bottles gained $\mathrm{O}_{2}$ (stored $\mathrm{C}$ ) while dark bottles lost $\mathrm{O}_{2}$ 

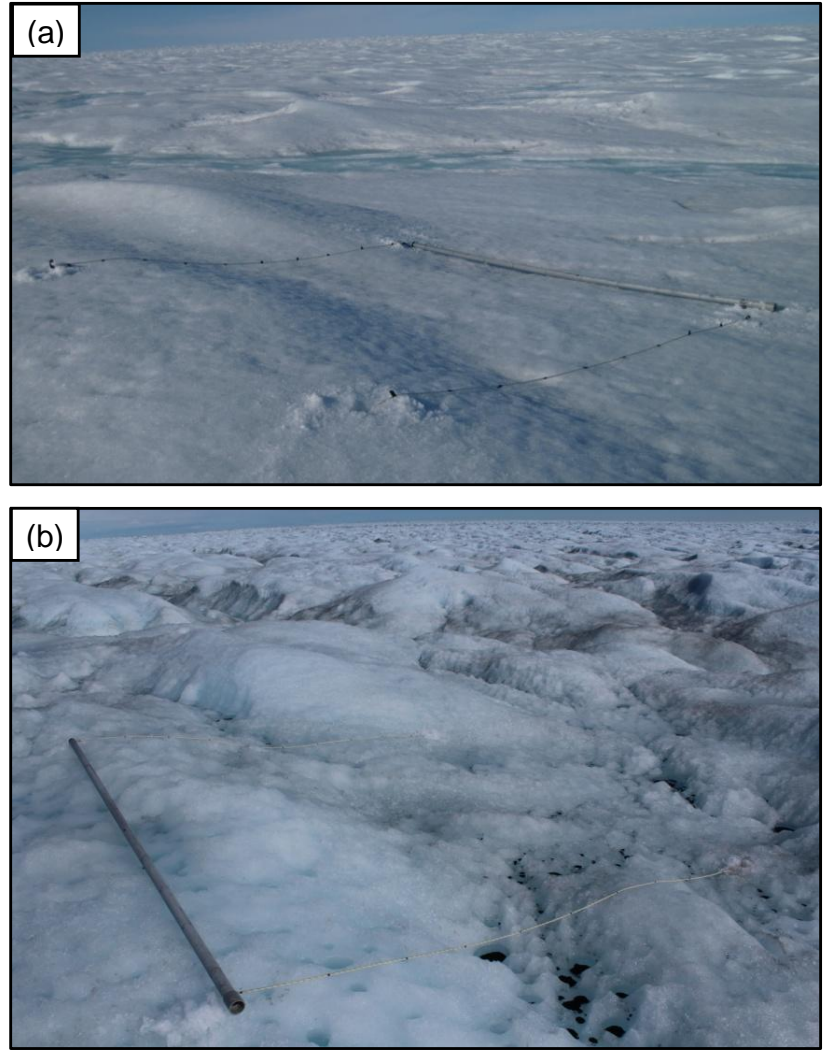

Figure 9. Quadrat Q3 on (a) 1 June 2012, with the pole on Row 12 and (b) 31 July 2012, with the pole on Row 1. The photos were taken looking approximately northeast. Note the darker and rougher surface on 31 July compared with 1 June.

(respired C). In contrast, CI samples significantly gained a very small but significant amount of $\mathrm{O}_{2}$ in both the light and dark bottles, by amounts that were not significantly different from each other (Fig. 7a; $p>0.05$ ). The greatest activity in the bottles was in OG, where mean photosynthesis and respiration rates were almost equal at $1.7 \mathrm{mgC} \mathrm{L}^{-1} \mathrm{~d}^{-1}$. Since the OG material was present in such small amounts, and observed at just one location, its contribution to carbon storage on the ice sheet is taken as negligible.

A better estimate of the variance within the main four sample types was provided by the additional incubation experiments with 24 bottles of the same type (12 light, 12 dark: Fig. 10). Although there was a wide spread of initial $\mathrm{O}_{2}$ concentrations, especially in the debris-rich CS and DI samples, the variability of changes in dissolved $\mathrm{O}_{2}$ after $24 \mathrm{~h}$ (which are the important results indicating the level of biological oxygen demand and inferred $\mathrm{C}$ storage) was much smaller. Specifically, standard deviations of $\Delta \mathrm{O}_{2}$ expressed as a fraction of the mean were $0.32,0.27,3.1$ and 0.30 in light bottles containing CI, DI, CW and CS, respectively, and 0.49, 0.32, 1.5 and 0.13 in the dark bottles, respectively. Each of these means is significantly different from zero $(p<0.05)$ except for those for CW.

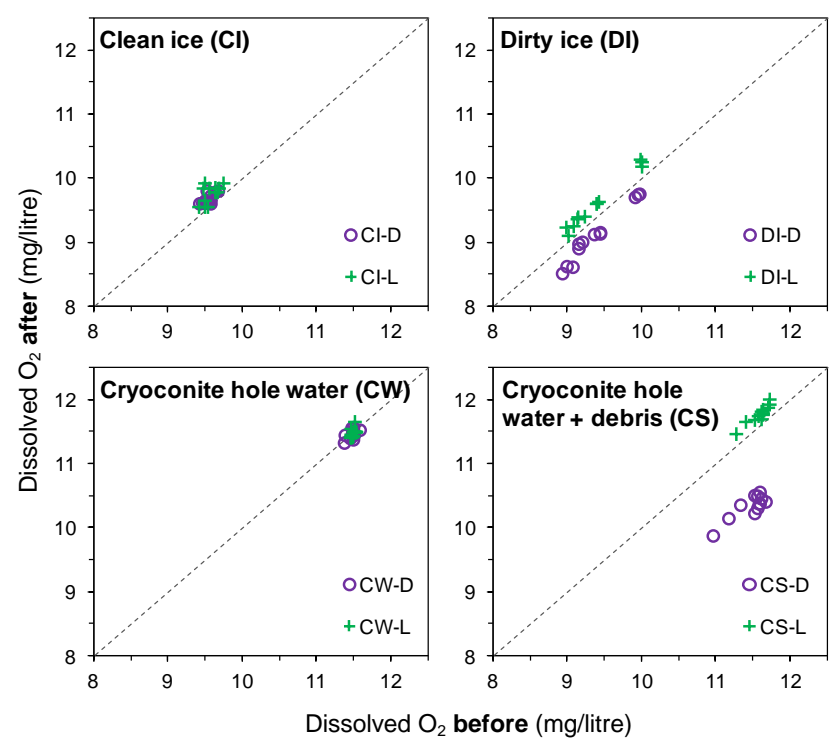

Figure 10. Dissolved $\mathrm{O}_{2}$ concentrations before and after incubation in experiments with 12 light (purple circles, "-L") and 12 dark bottles (green crosses, "-D") of each sample type. Samples plotting ABOVE the dashed line GAINED oxygen. Light samples indicate the balance between rates of respiration and photosynthesis, while dark samples reflect respiration rates only.

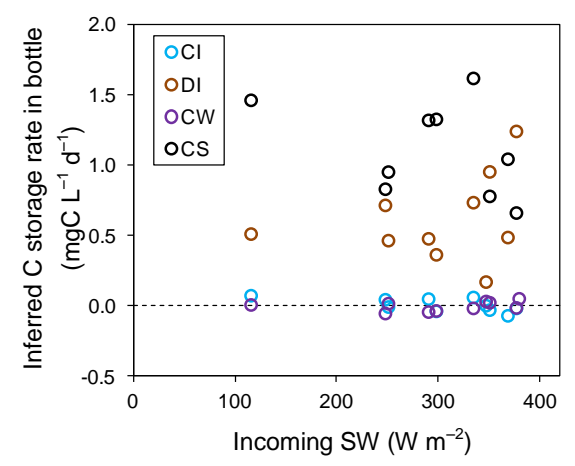

Figure 11. Relationship between incident SW radiation intensity and inferred $\mathrm{C}$ storage rate by photosynthesis, for clean ice (CI, blue), dirty ice (DI, brown), cryoconite holes ( $\mathrm{CH}$, black) and cryoconite hole water (CW, purple).

Seasonal variations in $\mathrm{C}$ storage rate within the bottles, as inferred from measured increases in dissolved $\mathrm{O}_{2}$, are shown in Fig. 7 for the four main surface types. There was no significant correlation in activity between activity between any two pairs of surface types (Spearman's rank correlation; $p>0.05$ ) and no clear seasonal pattern (Fig. 7), except for an apparently steady increase in the rates of photosynthesis and respiration in cryoconite hole (CS) samples from 11 June to 16 July. There was no significant correlation between incident $\mathrm{SW}$ radiation and $\mathrm{C}$ storage rate over the study period (Fig. 11); however, we found a strong link between incident SW intensity and productivity in the sub- $24 \mathrm{~h}$ activity exper- 


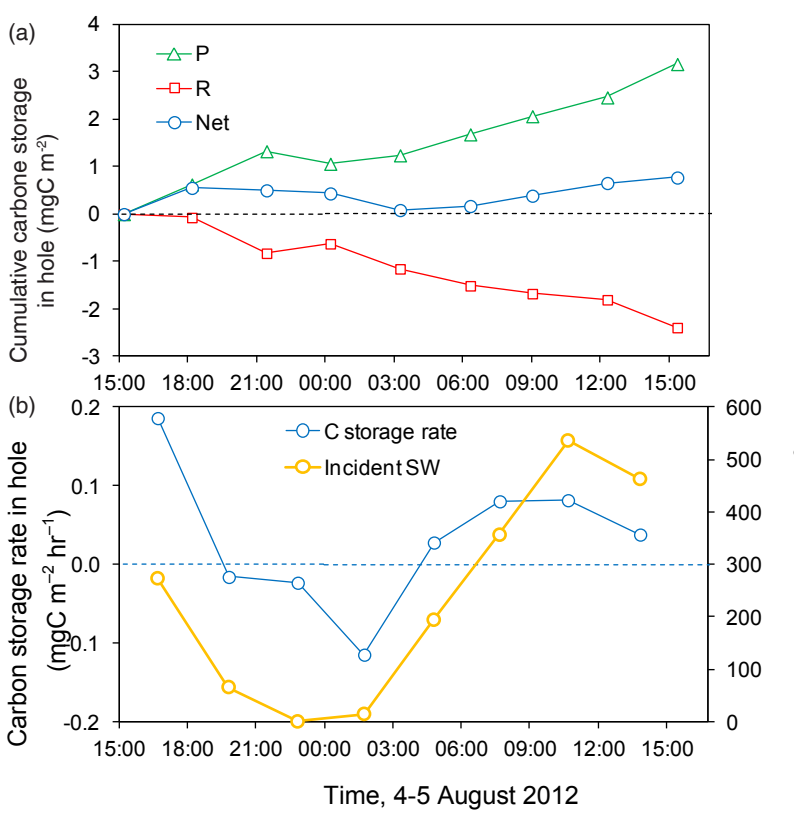

Figure 12. Changes in cryoconite hole $\mathrm{C}$ storage at sub-diurnal time scales. (a) Cumulative $\mathrm{C}$ storage as measured in bottles incubated for 3 to $24 \mathrm{~h}$. (b) Equivalent $\mathrm{C}$ flux in the same bottles as part (a), plotted alongside incident shortwave radiation intensity (3-h averages of 30-min data).

iment on 4-5 August (Fig. 12), which is in contrast to the seasonal results. These short incubations showed a change from $\mathrm{O}_{2}$ production ( $\mathrm{C}$ storage) to $\mathrm{O}_{2}$ storage $(\mathrm{C}$ release) during the darkest hours of the experiment (20:00-03:00 LT), but with an overall gain in dissolved $\mathrm{O}_{2}$ (net $\mathrm{C}$ storage) after $24 \mathrm{~h}$ consistent with the standard experiments.

Variations in productivity with cryoconite hole diameter and location were investigated in an experiment on 6-7 August, when samples from 15 holes in 5 areas were incubated (Fig. 13). Note that hole depth was not investigated in detail, because holes are typically encountered in rough, sloping ices surfaces such that the hole top is difficult to identify; the hole bases are also often sloping, and the water level relative to the ice surface can vary on a day-to-day basis depending on the melt crust thickness. Spearman's correlation between hole diameter and oxygen demand showed weak negative correlation between hole diameter and net productivity in the light bottles $(r=-0.52 ; p=0.027)$ and stronger negative correlation between hole diameter and respiration rate in the dark bottles $(r=-0.65 ; p=0.005)$ (Fig. 13a). There was no apparent difference in productivity between the five locations sampled (Fig. 13b).

Biological oxygen demand in the bottles was converted to net inferred $\mathrm{C}$ flux for each surface type, using estimates of the sampled ice area in each bottle and the contribution of each surface type to the total surface area as measured in the quadrat surveys. This yielded a seasonal pattern of $\mathrm{C}$ flux from each surface type (Fig. 14; Table 3) and an esti-

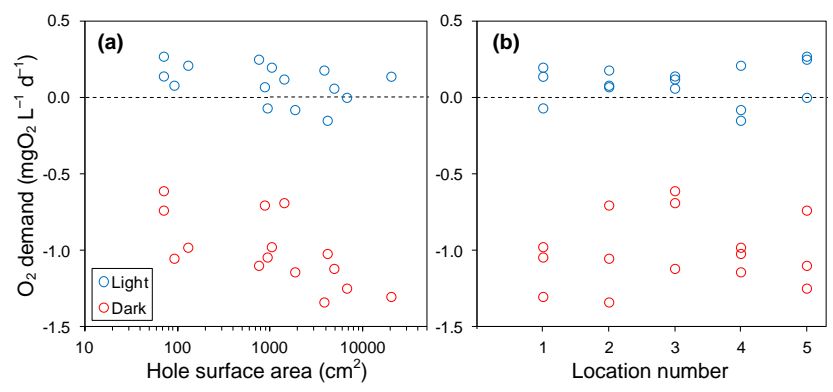

Figure 13. Variation in biological oxygen demand with (a) cryoconite hole surface area and (b) sampling location, 6-7 August 2012. To convert the measured $\mathrm{O}_{2}$ demand to inferred $\mathrm{C}$ storage in $\mathrm{mgC} \mathrm{m}^{-2} \mathrm{~d}^{-1}$, multiply the vertical axis values by 29.1 .

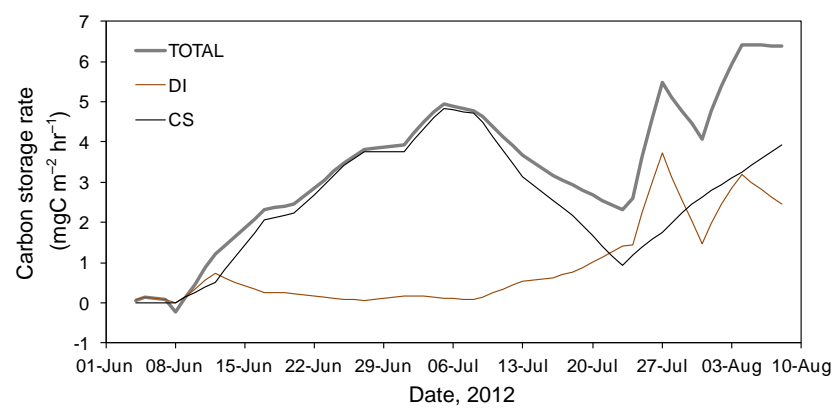

Figure 14. Seasonal variation in $C$ fluxes from the field site, showing individual contributions from DI and CS surfaces. Daily fluxes are plotted, which were calculated by linear interpolation of $\sim$ weekly incubation measurements and quadrat surveys.

mate of the total $\mathrm{C}$ flux at the field site during the summer study period of $3.4 \mathrm{mgC} \mathrm{m}^{-2} \mathrm{~d}^{-1}$. This mean was calculated from 66 daily values, each based on linearly interpolated quadrat and productivity data. The main contributions were $2.5 \mathrm{mgC} \mathrm{m}^{-2} \mathrm{~d}^{-1}$ from CS and $0.9 \mathrm{mgC} \mathrm{m}^{-2} \mathrm{~d}^{-1}$ from DI, while contributions from $\mathrm{SN}$ and $\mathrm{CW}$ were negligible. Note that $\mathrm{CI}$ was excluded from the total because the small gain in $\mathrm{O}_{2}$ appeared to be an artefact of the method (see Sect. 4.3).

\subsection{Albedo}

Daily albedo data satisfying the quality control criteria (Sect. 2.3) were available for 69 out of the 153 days from 1 May to 30 September (Fig. 6g). Albedo (reported as mean $\pm 1 \sigma$ ) from 1 to 25 May was $74 \pm 6 \%$ with no significant trend. After a sharp drop to $57 \pm 3 \%$ on 26 May, albedo fell unsteadily until early July, before stabilising at $39 \pm 2 \%$ from 8 July to 9 August. Following fresh snow on $10 \mathrm{Au}-$ gust, albedo was variable in the ca. $40-60 \%$ range before rising sharply on 1 September and remaining steady throughout that month at $73 \pm 3 \%$. 


\section{Discussion}

\subsection{Surface characteristics}

Results from the quadrat surveys, albedo retrieval and visual observations summarised above clearly demonstrate the great temporal and spatial variability in surface conditions at the field site. First, using observed patterns in surface classification and albedo we can divide the "summer" study period into four distinct periods, as follows.

- Period 1: pre-melt. Very little exposed ice before the winter snow has melted; cold, dry snow; no surface water; high albedo (> $70 \%$ ). In 2012, the field site was established on 26 May only a few hours before the onset of heavy rain marking the end of this period.

- Period 2: snow melt. 26-30 May. A rapid transition from dry snow to wet snow, slush, melt ponds and bare ice over just a few days, with a corresponding sharp drop in albedo. A similarly rapid transition was observed by $\mathrm{D}$. Chandler at a lower site $7 \mathrm{~km}$ from the margin $(\sim 600 \mathrm{~m}$ above sea level) in June 2011. Period 2 is likely to be relatively short in this part of the ice sheet, due to the very low precipitation in comparison with other parts of the west coast (Burgess et al., 2010).

- Period 3: early summer ice surface. 30 May-11 July. Superimposed ice and remaining snow patches gradually melt to reveal the dirty ice surface and cryoconite holes from the previous year. The area covered by cryoconite holes slowly increases to reach $\sim 17 \%$; albedo slowly decreases to a minimum $(34 \%)$.

- Period 4: late summer ice surface. 11 July-31 August. Cryoconite hole cover remains steady while dirty ice coverage varies widely, depending on prevailing weather conditions (warm/cloudy or cold/sunny); albedo remains low but becomes more variable. This period ends with an unsteady transition back to Period 1 conditions as evidenced by the snowfall on 10-11 August and similar events observed in the albedo record as peaks after the field campaign had ended.

Once cryoconite hole coverage had stabilised (Period 4), the mean areal coverage of $16.7 \%$ (range $12-27 \%$ in individual quadrat surveys) was much greater than that measured by Cook et al. (2012) on their nearby ablation-zone transect of sites at $\sim 67^{\circ} \mathrm{N}$, where maximum coverage was reported as $\sim 7 \%$ on $2-3$ August 2010 , but it is similar to coverage reported by Bøggild et al. (2010) along a transect of the very narrow ablation zone in northeast Greenland. Cook et al. (2012) analysed photographs of nine $1 \mathrm{~m} \times 1 \mathrm{~m}$ quadrats to determine cryoconite hole extent at each site, therefore sampling smaller areas (noting the high spatial variability indicated by error bars in Fig. 6). We argue that our strategy of five $2.7 \mathrm{~m} \times 2.7 \mathrm{~m}$ quadrats (total 500 measurements) will have yielded a more spatially representative sample at our field site. Photographic analysis should be used with caution since many of the deep but narrow cryoconite holes quickly become obscured as the viewing angle deviates from vertical: for example, a typical cryoconite hole $2 \mathrm{~cm}$ in diameter and $10 \mathrm{~cm}$ deep will be completely hidden in an image with a viewing angle of only $\tan ^{-1}(2 / 10)=11^{\circ}$ from vertical.

Despite the warm, cloudy conditions causing cryoconite holes to melt out and release their debris, resulting in the sharp increases in DI coverage following ablation peaks in July (Fig. 6), there was little corresponding reduction in $\mathrm{CH}$ coverage. This is probably because only the small, shallow holes melted out, and the debris contained in just a few holes is sufficient to create a much larger area of DI once it has been dispersed. The same conditions that lead to hole meltout also caused the surface to become hard and impermeable, making the rapid dispersion of debris much easier than would have been the case over the permeable, rough surface typical of sunny conditions. Another possible process that could increase DI coverage is input of windblown dust - however, it is unclear why this dust would immediately settle in patches rather than being generally distributed over the ice surface, so do we do not believe this process made a significant contribution. Overall, the combination of an early-summer increase in $\mathrm{CH}$ and late-summer increase in DI caused a steady decrease in the area of CI from $98 \%$ on 5 June to a minimum of $41 \%$ on 8 August.

The increasing areal coverage of cryoconite holes through the melt season was mainly due to the re-emergence of the previous year's holes, which we believe became exposed by the melting of superimposed ice, rather than the formation of new holes. We infer this because (1) the increasing $\mathrm{CH}$ area did not occur at the expense of DI, (2) excavation of DI surfaces revealed no visible debris below the ice surface, (3) there was no visible evidence of significant input of wind blown dust (most clean ice remained clean), and (4) because of our observations of thick $(>10 \mathrm{~cm})$ ice lids over newly emerging holes in June and July. These lids might have formed by refreezing of water in the hole over winter, by superimposed ice forming in snow above the hole, or both. In either case it seems likely that many holes can persist for more than one season, becoming reactivated in the spring as has been observed elsewhere: for example, the Dry Valleys, Antarctica (Fountain et al., 2004). Some emerging holes had lids with a radial crystal structure characteristic of re-freezing processes, and were easy to spot in the rotting ice surface; others had little or no surface expression and were found only after the lid collapsed under foot pressure (we speculate that these lids are more likely to consist of superimposed ice; their remains are shown in Fig. 8b). The large number of cryoconite holes apparently present beneath the surface early in the season suggests that most holes persisted through the winter. Interannual observations are still needed to confirm this. At present it is uncertain how long the holes 
are active for in the spring before losing their winter ice lids, and this early season activity has yet to be measured.

Field data for this study were collected in 2012, which was notable for its unusually warm conditions across the whole ice sheet: in particular regarding the record-breaking melt extent and surface mass balance (Tedesco et al., 2013). Nevertheless, similarities between the seasonal changes in albedo observed in the present and previous studies (for example Knap and Oerlemans, 1996; Stroeve et al., 2001) suggest the pattern discussed above is persistent between years, including this extreme melt year. Extended visits to the same site in 2011 (25 June-8 July; 31 July; 12-20 August) have also allowed qualitative visual comparison of the ice surface between the two summers. Many features were recognised in both seasons: the gradual exposure of cryoconite holes from under ice lids; patchiness of dirty ice coverage; increasing amplitude of the surface lumpiness as the melt season progresses. The only noted difference of significance was the frequent occurrence of warm, cloudy and windy conditions in July and August 2012 (Fig. 6), which created a hard and slippery ice surface and caused melt-out of some of the cryoconite holes - these events were not observed in 2011, when conditions were predominantly cooler and sunnier. This suggests a greater contribution of sensible or latent heat fluxes to surface melt in 2012.

The presence of the melt crust has interesting implications for ice ablation observations based solely on surface height, when these are used to determine ice mass loss. If the melt crust were to maintain constant characteristics (density, thickness) then surface height change is directly correlated with ice mass loss, usually expressed in mm water equivalent. However, changes in the melt crust will introduce erroneous ablation estimates when using this approach: most significantly a strong overestimate of ablation at the onset of warm conditions, when the melt crust is stripped to leave a solid ice surface. Similarly, following the return to cold, sunny conditions, there will be an artificial dip in observed ice mass loss as the melt crust reforms, since ice is being lost from a layer several $\mathrm{cm}$ thick with little change in surface height.

\subsection{Ice surface albedo}

The mean albedo of $45 \%$ reported by Knap and Oerlemans (1996) for Zone II of the ablation zone on 25 July 1991 is similar to that retrieved from the 2012 AVHRR data for our field site once the albedo had stabilised early in Period 4 ( $39 \pm 2 \%$ from 8 July to 9 August). The seasonal changes in albedo (Fig. 6g) followed a similar pattern to observations from this part of the ice sheet in previous remote sensing and AWS studies, in particular the gradual decrease in Period 3: for example at Site S6 on the K-transect, located at the same altitude $(1030 \mathrm{~m})$ as the present field site (Knap and Oerlemans, 1996). However, while Knap and Oerlemans (1996) attributed albedo changes solely to variations in surface melt, the gradual decrease in albedo observed in our Period 3 oc- curred when there was an overall decrease in stored surface water and slush as the surface drainage system developed. Therefore, while the initial sharp drop at the end of May was due to a transition from loose, dry snow encountered on arrival at the site to water ponds and wet snow, the subsequent gradual decrease in albedo between 29 May and 10 July was more likely due to increasing exposure of cryoconite holes than to increasing melt water coverage (Fig. 6). This is consistent with the recent work of Wientjes et al. (2011). These two distinctly different responses demonstrate the ability of surface albedo retrievals to provide information on both surface melt and surface cryoconite hole coverage.

\subsection{Surface productivity}

Throughout the season, dirty ice (DI) and cryoconite waterplus-sediment (CS) incubations consistently showed $\mathrm{O}_{2}$ loss in dark bottles and slight but significant $\mathrm{O}_{2}$ gain in light bottles (Fig. $7 \mathrm{~b}$ and c) corresponding to net $\mathrm{C}$ storage (see Sect. 3.2) indicative of active, weakly autotrophic biological communities as have been observed previously in cryoconite holes in Greenland and elsewhere (Anesio et al., 2009; Cook et al., 2012). In contrast, there was slight $\mathrm{O}_{2}$ gain in both light and dark clean ice (CI) incubations (Fig. 7a), with $\mathrm{O}_{2}$ gains found to be insignificantly different between the light and dark bottles. This $\mathrm{O}_{2}$ gain was therefore a light-independent process and was most likely an artefact of the method, for example a small amount of $\mathrm{O}_{2}$ may have been absorbed by the water when the oxygen probe was inserted to take the postincubation reading. This problem would have had a greater effect in melted ice samples (CI, DI) than water samples (CW, CS) as melted ice samples were under-saturated with $\mathrm{O}_{2}$ following melting: compare CI, DI starting $\mathrm{O}_{2}$ levels with those of CW, CS in Fig. 10. Correcting the DI results for this same artefact would reduce the total $\mathrm{O}_{2}$ gain by about $30 \%$, from 1.1 down to $0.8 \mathrm{mgO}_{2} \mathrm{~L}^{-1} \mathrm{~d}^{-1}$. We also note that the measured DI productivity may not be a true representation of in situ rates since we were using melted samples. Firstly, the solar radiation may have been weaker in the incubation environment than at the ice surface owing to the shading effect of the hole edges; secondly, the nutrient concentrations may have been altered during melting, for example with some chemical species becoming more diluted when water within the grain boundaries in the rotting surface ice was mixed with bulk melt from the surrounding crystals. In situ measurements in ice would be extremely challenging, due to the open nature of the system (ice permeable to water and gases) and ice-water exchange of solutes during melting-refreezing processes. Nevertheless, our measurements represent the potential for activity in this surface environment.

In contrast to the clear seasonal changes in the ice surface characteristics, there was very little evidence for any seasonal signal in the results of productivity experiments, except for a general increase in $\mathrm{O}_{2}$ consumption in cryoconite holes during Period 3 (Fig. 7c). This trend did not significantly al- 
ter the net productivity so was presumably balanced by increasing photosynthesis, suggesting a strong link between the rates of respiration and photosynthesis similarly to results reported by Hodson et al. (2010) and Telling et al. (2012a) but contrary to others (for example, net respiration: Stibal and Tranter, 2007). In our case, increasing respiration may reflect the increasing exposure time of holes to direct solar radiation following melting of the ice lids (i.e. increasing cell count), or a thicker accumulation of sediment. Unfortunately the sediment was always too thin (up to a few $\mathrm{mm}$ ) to allow accurate thickness measurements. Interestingly, both the surface area and activity of cryoconite holes increased during Period 3, then remained steady in early Period 4, mirroring the surface albedo (decreasing in Period 3, steady in early Period 4). Total C flux into cryoconite holes increased during this time due to an increase in the area of exposed holes rather than changes in net productivity (Fig. 14).

Combining results from the quadrat and BOD experiments yielded total $\mathrm{C}$ fixation over the course of the experiment (4 June-9 August) of $0.22 \mathrm{gC} \mathrm{m}^{-2}$, of which DI and CS contributed 26 and $74 \%$, respectively. The melt season continued beyond the end of the experiment, probably by $\sim 3$ weeks according to the albedo data, so the total flux for the complete season was most likely greater (simple extrapolation would yield $0.29 \mathrm{gC} \mathrm{m}^{-2}$ ). However, the annual net $\mathrm{C}$ flux remains uncertain since the summer is relatively short and for much of the year there is either no daylight or the ice surface is covered by highly reflective snow which greatly reduces light intensity reaching the microbial communities beneath. Since high rates of respiration were recorded in dark bottles it is evident that any $\mathrm{C}$ stored during the summer might be subsequently released over the winter. The effect of this on annual fluxes will be dependent on the continuation of microbial activity in the extended periods without sunlight. Whilst much of this period is very cold, solute-rich water remains in the grain boundaries surrounding the ice crystals, which could allow microbial activity albeit at much reduced rates. This could have a significant effect on carbon fluxes and should clearly be addressed in future studies in Greenland.

The short term experiment with cryoconite hole sediment demonstrates the necessity of using incubations lasting for multiples of $24 \mathrm{~h}$ to minimise the effects of diurnal variations in activity driven by solar radiation intensity (Fig. 12). However, despite the clear dependency of radiation intensity on productivity at diurnal time scales, there was no clear relationship between activity and radiation intensity at seasonal time scales (Fig. 11), so we assume the incoming solar radiation intensity did not contribute significantly to the seasonal variability in productivity. Instead, other factors such as hole age, hole depth, debris composition, debris thickness or water chemistry may have been important. Interestingly, Stibal et al. (2012) found slope angle was an important factor along their ablation zone transect at $67^{\circ} \mathrm{N}$. However, their slopes were computed from GPS positions separated by many kilo- metres and are unlikely to reflect the local slope angle owing to the very rough ice sheet surface in the ablation zone at the horizontal scale of 1 to $100 \mathrm{~m}$ (compare local slopes in Figs. 2 and 9 with the calculated topographic slope of less than $\left.1^{\circ}\right)$. The correlation reported by Stibal et al. (2011) is therefore unlikely to be a direct causal relationship.

In the same region of the ice sheet as our field site, Hodson et al. (2010) reported mean $\mathrm{C}$ storage rates in cryoconite holes of $-3.9 \mu \mathrm{gC} \mathrm{g}^{-1} \mathrm{~d}^{-1}$, which is equivalent to $-8.0 \mathrm{mgC} \mathrm{m}^{-2} \mathrm{~d}^{-1}$ using their value of $0.206 \mathrm{~g} \mathrm{~cm}^{-2}$ of sediment in cryoconite holes. At Transect Site 7, representative of our field site, Stibal et al. (2011) measured NEP, photosynthesis, respiration $\mathrm{C}$ storage rates of $1.1 \pm 0.5,-4.9 \pm$ $1.8,3.8 \pm 2.0 \mathrm{mgC} \mathrm{m}^{-2} \mathrm{~d}^{-1}$ (based on results reported in $\mu g \mathrm{Cm}^{-2} \mathrm{~d}^{-1}$ converted to $\mathrm{mgC} \mathrm{g}^{-1} \mathrm{~d}^{-1}$ using their measured surface debris cover of $180 \mathrm{~g} \mathrm{~m}^{-2}$ ). By comparison, $\mathrm{C}$ fluxes from cryoconite holes in our study ranged from 5 to $33 \mathrm{mgC} \mathrm{m}^{-2} \mathrm{~d}^{-1}$ (mean $24 \mathrm{mgC} \mathrm{m}^{-2} \mathrm{~d}^{-1}$ ). Our data and those of previous studies highlight the great variability in measured $\mathrm{C}$ fluxes associated with microbial activity; even the direction of the flux ( $\mathrm{C}$ storage or $\mathrm{C}$ release) varies between studies.

\subsection{Linking albedo and productivity}

Since there is a clear response of the AVHRR-derived albedo to the snow melt and increasing cryoconite hole exposure (Fig. 6; Periods P3-P4), it is likely that a relationship could be established between retrieved albedo and cryoconite hole coverage. This is illustrated in Fig. 15, which shows a clear link between albedo and cryoconite hole coverage as well as between albedo and net surface productivity. A robust relationship based on remotely sensed albedo would enable a much more wide-ranging assessment of cryoconite hole coverage than has been possible in this or previous field studies, and could also be used to predict surface $\mathrm{C}$ fluxes either directly (Fig. 15, bottom panel) or indirectly via the hole coverage and hole productivity. The scatter evident in Fig. 15 shows there would be a large uncertainty associated with any prediction of $\mathrm{C}$ flux based on albedo from this data set alone, but this uncertainty is nevertheless smaller than that associated with extrapolation of point measurements collected in isolation and could be reduced either with further observations or by analysis of data from previous studies given that AVHRR data are available for periods covering the studies listed in Table 1.

The albedo product used here appeared less sensitive to DI coverage, but it is worth noting that the sudden increases in DI during high melt events occurred exclusively in periods of cloudy weather, when albedo data are not available from satellite remote sensing, so it does not seem likely that AVHRR data will be useful for assessing DI coverage. Further, there was great spatial variability in DI cover (Fig. 6c), making it difficult to correlate albedo and DI cover with a relatively small data set. The contribution of DI to the mean 

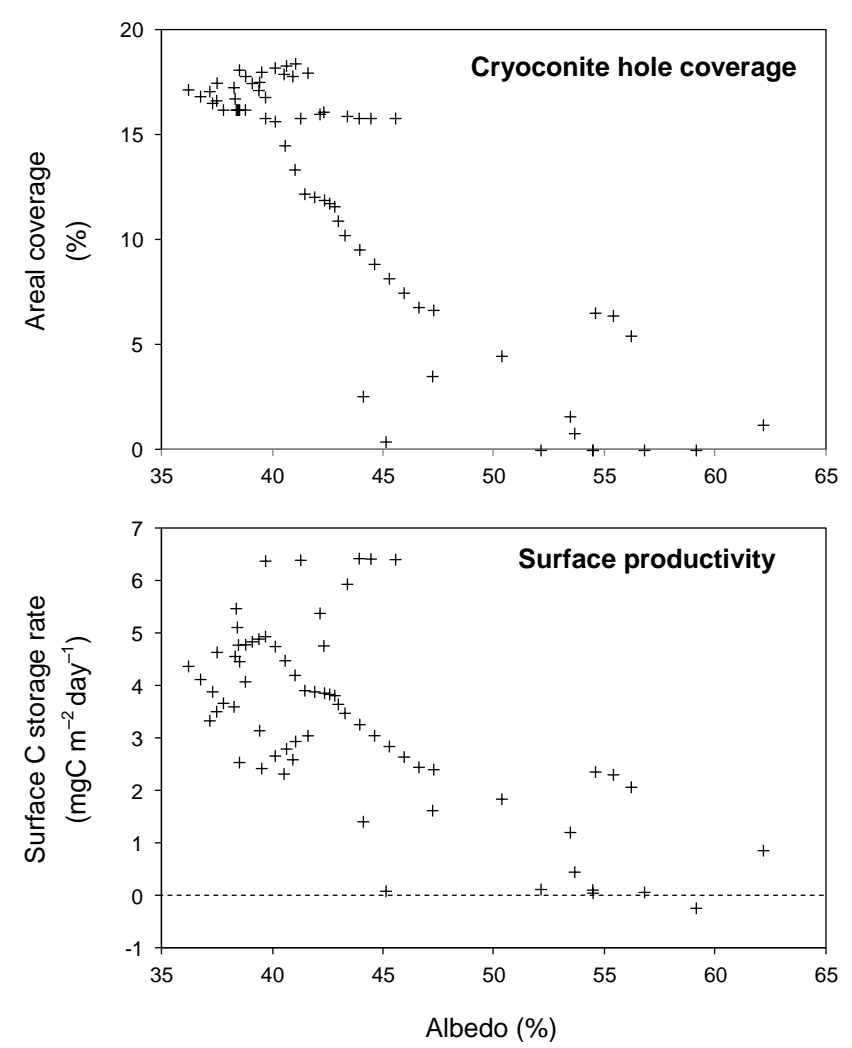

Figure 15. Correlations between albedo and cryoconite hole coverage (top) and between albedo and surface productivity (bottom). Each point is a daily value, linearly interpolated from the respective time series since observations of each quantity were generally not made simultaneously.

C flux was approximately one-third that of cryoconite holes; therefore, an alternative approach to measuring DI coverage remotely may be needed if the DI contribution is included in this approach to estimating ice sheet $\mathrm{C}$ fluxes.

\section{Conclusions}

A time-series of ice surface characteristics and productivity from 26 May to 10 August 2012 has provided a detailed insight into seasonal changes in ice surface processes during the melt season. The field site was located about half way between the ice margin and equilibrium line in west Greenland, near the edge of the so-called "dark zone" of the Greenland Ice Sheet's ablation zone (Wientjes et al., 2011). Specific findings of interest are as follows:

1. Based on changes in ice surface characteristics observed in ground observations and satellite AVHRR imagery, the melt season was classified into four distinct periods. These are: winter snow cover (P1); snow melt (P2); melting of superimposed ice and exposure of cryoconite holes (P3); and the mid- to late-summer ice surface (P4).
2. There was a marked surface response to major melt events, most notably expressed as loss of the several centimetre-thick, permeable melt crust to expose the impermeable underlying ice, and the dispersion of debris from shallow cryoconite holes.

3. In situ incubation experiments revealed active microbial communities, as have been reported in limited previous studies in Greenland. Rates of activity in the different ice surface environments were very variable both between environments and between incubations in the same environment. There was no clear seasonal signal, aside from apparent correlations between albedo, cryoconite hole coverage and cryoconite hole productivity in melt season Periods 3 and 4. These correlations were mostly attributed to changes occurring in Period 3. On average over the full study period, we found significant net $\mathrm{O}_{2}$ production (inferred as net $\mathrm{C}$ storage) in dirty ice and cryoconite holes. There was no significant $\mathrm{O}_{2}$ gain or loss in snow or water samples.

While there is good evidence from this and previous studies that seasonal changes in ice surface characteristics are broadly persistent between years, the very variable productivity results obtained at this field site and elsewhere suggest that there remains great uncertainty in the magnitude of biologically mediated carbon fluxes into the ablation zone of the ice sheet. However, the link between cryoconite hole productivity, cryoconite hole areal coverage and ice surface albedo shows there is potential for the large-scale estimation of biological processes and associated carbon fluxes, which could aid in extrapolating point observations up to the ablation zone scale. However, the areas of dirty ice also contribute significantly to carbon fluxes but a similar correlation between dirty ice coverage and albedo was not apparent.

Acknowledgements. This work was funded by NERC grant no. NE/H023879/1. M. van den Broeke (IMAU) kindly provided the meteorological data, and AVHRR imagery was supplied by the EUMETSAT Climate Monitoring Satellite Application Facility (CM SAF). We thank the three reviewers for their detailed comments on the original version of the paper.

Edited by: E. Larour 


\section{References}

Anesio, A. M., Hodson, A. J., Fritz, A., Psenner, R., and Sattler, B.: High microbial activity on glaciers: importance to the global carbon cycle, Glob. Change Bio., 15, 955-960, doi:10.1111/j.13652486.2008.01758.x, 2009.

Bayley, W. S.: Minerology and petrography, Am. Natur., 25, 138146, 1891.

Bøggild, C. E., Brandt, R. E., Brown, K. J., and Warren, S. G.: The ablation zone in northeast Greenland: ice types, albedos and impurities, J. Glaciol., 56, 101-113, 2010.

Burgess, E. W., Forster, R. R., Box, J. E., Mosley-Thompson, E., Bromwich, D. H., Bales, R. C., and Smith, L. C.: A spatially calibrated model of annual accumulation rate on the Greenland Ice Sheet (1958-2007), J. Geophys. Res., 115, F02004, doi:10.1029/2009JF001293, 2010.

Cook, J. M., Hodson, A. J., Anesio, A. M., Hanna, E., Yallop, M., Stibal, M., Telling, J., and Huybrechts, P.: An improved estimate of microbially mediated carbon fluxes from the Greenland Ice Sheet, J. Glaciol., 58, 1098-1108, doi:10.3189/2012JoG12J001, 2012.

Duynkerke, P. G. and van den Broeke, M. R.: Surface energy balance and katabatic flow over glacier and tundra during GIMEX91, Global Planet. Change, 9, 17-28, 1994.

Fountain, A. G., Tranter, M., Nylen, T. H., Lewis, K .J., and Mueller, D. R.: Evolution of cryoconite holes and their contribution to runoff from glaciers in the McMurdo Dry Valleys, Antarctica, J. Glaciol., 50, 35-45, 2004

Greuell, W., Denby, B., Van der Wal, R. S. W., and Oerlemans, J.: 10 years of mass-balance measurements along a transect near Kangerlussuaq, central West Greenland, J. Glaciol., 47, 157-158, 2010.

Hodson, A., Anesio, A. M., Ng, F., Watson, R., Quirk, J., IrvineFynn, T., Dye, A., Clark, C., McCloy, P., Kohler, J., and Sattler, B,: A glacier respires: Quantifying the distribution and respiration $\mathrm{CO}_{2}$ flux of cryoconite across an entire Arctic supraglacial ecosystem, J. Geophys. Res.-Biogeo., 112, G04S36, doi:10.1029/2007JG000452, 2007.

Hodson, A., Bøggild, C., Hanna, E., Huybrechts, P., Langford, H., Cameron, K., and Houldsworth, A.: The cryoconite ecosystem on the Greenland Ice Sheet, An. Glaciol., 51, 123-129, 2010.

Irvine-Fynn, T. D. L., Bridge J. W., and Hodson, A.: In situ quantification of supraglacial cryoconite morphodynamics using timelapse imaging: an example from Svalbard, J. Glaciol., 57, 651657, 2011.

Karlsson, K-G., Riihelä, A., Müller, R., Meirink, J. F., Sedlar, J., Stengel, M., Lockhoff, M., Trentmann, J., Kaspar, F., Hollmann, R., and Wolters, E.: CLARA-A1: CM SAF Clouds, Albedo and Radiation dataset from AVHRR data - Edition 1 - Monthly Means/Daily Means/Pentad Means/Monthly Histograms, Satellite Application Facility on climate Monitoring, doi:10.5676/EUM_SAF_CM/CLARA_AVHRR/V001, 2012.

Knap, W. H. and Oerlemans, J.: The surface albedo of the Greenland ice sheet: satellite-derived and in situ measurements in the Søndre Strømfjord area during the 1991 melt season, J. Glaciol., 42, 364-374, 1996.

Konzelmann, T. and Braithwaite, R. J.: Variations of ablation, albedo and energy balance at the margin of the Greenland ice sheet, Kronprins Christian Land, eastern north Greenland, J. Glaciol., 41, 174-182, 1995.
Langford, H., Hodson, A., Banwart, S., and Bøggild, C.: The microstructure and biogeochemistry of Arctic cryoconite granules, Ann. Glaciol., 51, 87-94, 2010.

Nolin, A. W. and Payne, M. C.: Classification of glacier zones in western Greenland using albedo and surface roughness from the Multi-angle Imaging SpectroRadiometer (MISR), Remote Sens. Environ., 107, 264-275, 2007.

Nolin, A. W., Fetterer, F. M., and Scambos, T. A.: Surface roughness characterizations of sea ice and ice sheets: Case studies with MISR data, IEEE T. Geosci. Remote, 40, 1605-1615, 2002.

Oerlemans, J. and Vugts, H. F.: A meteorological experiment in the melting zone of the Greenland ice sheet. Bull. Am. Meteorol. Soc., 74, 355-365, 1993.

Schaepman-Strub, G., Schaepman, M. E., Painter, T. H., Dangel, S., and Martonchik, J. V.: Reflectance quantities in optical remote sensing - definitions and case studies, Remote Sens. Environ., 103, 27-42, 2006.

Smeets, C. J. P. P. and van den Broeke, M. R.: Temporal and spatial variations in the aerodynamic roughness length in the ablation zone of the Greenland Ice Sheet, Bound-Lay. Meteorol., 128, 315-338, doi:10.1007/s10546-008-9291-0, 2008.

Steinböck, O.: Über Kryokonitlöcher und ihre biologische Bedeutung, Z. Gletscherkd., 24, 1-21, 1936.

Stibal, M. and Tranter, M.: Laboratory investigation of inorganic carbon uptake by cryoconite debris from Werenskioldbreen, Svalbard, J. Geophys. Res., 112, G04S33, doi:10.1029/2007JG000429, 2007.

Stibal, M., Telling, J., Cook, J., Mak, K. M., Hodson, A., and Anesio, A. M.: Environmental controls on microbial abundance and activity on the Greenland Ice Sheet: a multivariate analysis approach, Microb. Ecol., 63, 74-84, doi:10.1007/s00248-0119935-3, 2012.

Stroeve, J.: Assessment of Greenland albedo variability from the advanced very high resolution radiometer Polar Pathfinder data set, J. Geophys. Res., 106, 33989-34006, 2001.

Takeuchi, N.: Optical characteristics of cryoconite (surface dust) on glaciers: the relationship between light absorbency and the property of organic matter contained in the cryoconite, Ann. Glaciol., 34, 404-419, 2002.

Tedesco, M., Fettweis, X., Mote, T., Wahr, J., Alexander, P., Box, J. E., and Wouters, B.: Evidence and analysis of 2012 Greenland records from spaceborne observations, a regional climate model and reanalysis data, The Cryosphere, 7, 615-630, doi:10.5194/tc7-615-2013, 2013.

Telling, J., Anesio, A. M., Hawkins, J., Tranter, M., Wadham, J. L., Hodson, A. J., Irvine-Fynn, T., and Yallop, M. L.: Measuring rates of gross photosynthesis and net community production in cryoconite holes: a comparison of field methods, Ann. Glaciol., 51, 153-162, 2010.

Telling, J., Anesio, A. M., Tranter, M., Stibal, M., Hawkings, J., Irvine-Fynn, T., Hodson, A., Butler, C., Yallop, M., and Wadham, J. L.: Controls on the autochthonous production and respiration of organic matter in cryoconite holes on High Arctic glaciers, J. Geophys. Res.-Biogeo., 117, G01017, doi:10.1029/2011JG001828, 2012a.

Telling, J., Stibal, M., Anesio, A. M., Tranter, M., Nias, I., Cook, J., Bellas, C., Lis, G., Wadham, J. L., Sole, A., Nienow, P., and Hodson, A.: Microbial nitrogen cycling on the Greenland Ice 
Sheet, Biogeosciences, 9, 2431-2442, doi:10.5194/bg-9-24312012, 2012b.

Uetake, J., Naganuma, T., Hebsgaard, M. B., Kanda, H., and Koshima, S.: Communities of algae and cyanobacteria on glaciers in west Greenland, Polar Science, 4, 71-80, 2010.

van de Wal, R. S. W. and Oerlemans, J.: An energy balance model for the Greenland Ice Sheet, Global Planet. Change, 9, 115-131, 1994.

Wientjes, I. G. M., Van de Wal, R. S. W., Reichart, G. J., Sluijs, A., and Oerlemans, J.: Dust from the dark region in the western ablation zone of the Greenland ice sheet, The Cryosphere, 5, 589-601, doi:10.5194/tc-5-589-2011, 2011.
Yallop, M. L., Anesio, A. M., Perkins, R. G., Cook, J., Telling, J., Fagan, D., MacFarlane, J., Stibal, M., Barker, G., Bellas. C., Hodson, A., Tranter, M., Wadham, J., and Roberts, N. W.: Photophysiology and albedo-changing potential of the ice algae community on the surface of the Greenland ice sheet, ISME Journal, 6, 2302-2313, 2012. 